\title{
[Fábricas y redes] culturales. Patrimonio Industrial estratégico para conectar el territorio
}

\author{
SELECCIÓN IX SEMINARIO INTERNACIONAL DE INVESTIGACIÓN EN URBANISMO
} Barcelona \& Bogotá, jun. 2017.

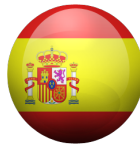

\section{Kyra Romero Branchadell}

Arquitecta, estudiante del Máster de Investigación en Urbanismo. Universidad Politécnica de Cataluña. Barcelona [Cataluña] España. <kyra.rb@outlook.com>

Colaboradores / Orientadores:

Joaquín Sabaté Bel \& Melisa Pesoa (directores de la tesina en curso).

https://upcommons.upc.edu/bitstream/handle/2117/108333/62BCN_RomeroKyra.pdf?sequence=1\&isAllowed=y

\begin{abstract}
Resumo
Las instituciones públicas están promoviendo la cultura como motor de desarrollo sostenible y equitativo, ubicando equipamientos culturales en diferentes puntos de la ciudad y del territorio. Estos centros están conectados mediante redes, colonizan espacios que antes tenían otros usos y actúan más allá de sus propios muros. Para comprender mejor y constatar el incremento en la complejidad de la relación entre el museo y la ciudad, se analizan diferentes casos de la provincia de Barcelona. En concreto, se estudian las redes del Museo de Historia de Barcelona (MUHBA) y del Sistema Territorial del Museo Nacional de la Ciencia y la Técnica de Cataluña(mNACTEC), incluyendo 4 de sus sedes, todas ellas públicas y ubicadas en antiguas fábricas. Se introduce el concepto de Fábrica Cultural, elementos patrimoniales industriales reconvertidos en museos, que por su representatividad, configuración y emplazamiento, juegan un rol estratégico de interconexión entre diferentes escalas y fragmentos de ciudad. Por ello, el objetivo de nuestra investigación en curso es explicar la descentralización de estos museos y sus relaciones, como claves que permiten a las redes culturales generar tejidos urbanos y sociales más cohesionados, más sensibles con su pasado y más preparados para su futuro.
\end{abstract}

\section{Palabras clave}

Patrimonio. Museos. Regeneración urbana. Redes territoriales.

\section{Cultural [factories \& networks]. Strategic Industrial Heritage to organize the territory}

\begin{abstract}
Public institutions are fostering culture as a sustainable and equitable development driving force, by locating cultural facilities in different points of the city and the territory. These centres are connected by networks, located in spaces that were previously used in a different ways, and that extend their activities beyond their walls. To better understand and confirm the increasing complexity of the relationship between the museum and the city, we analyse different case-studies in the province of Barcelona. We specifically study the networks of Barcelona History Museum (MUHBA) and the Regional Structure of the National Science and Technology Museum of Catalonia (mNACTEC), including 4 centres, all of them public and located in former factories. We introduce the concept of Cultural Factory, industrial heritage transformed into museum that play a strategic role connecting different scales and fragments of the city, thanks to its representativeness, configuration and location. Therefore, the objective of our ongoing research is to explain the decentralization of this museums and its relationships, as a key that allow cultural networks to build more cohesive neighbourhoods, more sensitive with their past, and ready for their future.
\end{abstract}

\section{Keywords}

Heritage. Museums. Urban regeneration. Regional networks. 


\title{
1. Conceptos clave para entender las fábricas culturales
}

\begin{abstract}
"Debemos favorecer actividades que trabajen con los "materiales de la memoria": sensibles al entorno, viables económicamente, didácticas, que generen empleo, que empoderen a la comunidad local y les inciten a formar parte de las soluciones para el futuro" (Pol Méndez 1999, p.113).
\end{abstract}

Infraestructuras y sistemas de comunicación conectan el mundo de una forma sin precedentes que nos obliga a repensar cómo influyen las corrientes migratorias y cómo diseñamos nuestras ciudades. Conceptos como resiliencia o diversidad ganan importancia ante un panorama cambiante, producido por la sociedad del conocimiento. Para esta sociedad, la innovación y el emprendimiento son claves para adaptarse, o incluso generar los cambios que mantienen el sistema activo, o lo que es lo mismo, vivo. Todo ello produce un incremento en la complejidad de nuestras redes a todas las escalas. Redes que conectan no sólo territorios o servicios, sino ideas. En este contexto de cambio y crecimiento frenético, ninguna ciudad quiere quedar fuera del mapa y la cultura juega un papel fundamental, conectando su comunidad, con otras, a escala global y local. Además, como plantea Richard Florida (2009, original 2002) en Ciudades Creativas, las redes interconectan diferentes puntos en unas mega-regiones unidas por el afán creativo y la identidad propia. El propio autor reconoce el entorno de Barcelona como la onceava megaregión mundial, ¿qué la hace tan especial?

En Cataluña la industrialización constituye un periodo que permitió desarrollar o mantener una identidad propia, diferente de la de su entorno. Su proceso de "modernización significó que en los aspectos productivos, sociales y culturales tuviera un liderazgo dentro de España" (Casanelles i Rahola, 2013, p.22). Con la transformación tecnológica y la deslocalización, el sector textil entró en declive. Muchas empresas cerraron, dejando atrás fantásticas estructuras, bien comunicadas e intrincadas en el entorno urbano. Con el paso del tiempo, muchas fueron desapareciendo, despertando movimientos populares e intelectuales que luchaban por su recuperación. En Barcelona "A raíz de los Juegos Olímpicos se produjo un cambio de orientación urbanística de la ciudad hacia proyectos de reconversión de suelo industrial" (Tatjer, 2006). El reclamo de intelectuales, ingenieros, historiadores, artistas y vecinos, permitió dar el empuje necesario para proteger y recuperar elementos del Patrimonio Industrial de Barcelona para fines cívicos. En este contexto, dos instituciones han contribuido a dar a conocer, generar sensibilidad y mantener el patrimonio industrial: a nivel regional el museo Nacional de la Ciencia y la Técnica o mNACTEC y a nivel urbano el Museo de Historia de Barcelona o MUHBA.

Se ha escrito mucho sobre la contribución de los museos a la sociedad en el ámbito económico (Matarosso, 1997; Williams, 1997; Sandell, 1998; Sheppard, 2000; Persson, 2000; Evans, 2001; Parker, Waterston, Michaluk \& Rickard, 2002 and Holden, 2004), o social, con estudios tan destacados, como, por ejemplo, Measuring the impact of museums on their communities: The role of the 21st century museum (Kelly, 2006). Si bien resulta un tema recurrente, esta investigación se centra en la discusión del vínculo entre cultura y ciudad. Esta relación parte de obras recientes, como el Informe Global de la UNESCO, Culture Urban Future (2016), o los libros Cities, Museums and Soft Power, (G. Lord y N. Blankenberg 2015) y Culture, Urbanism and Planning (Monclús, 2006). En este último se destaca la influencia de la cultura en el urbanismo actual. Así como el peso de la economía cultural se reconoce a partir de 1970, primero en las ciudades norteamericanas y luego en otras metrópolis occidentales, el planeamiento convencional dio paso al Urbanismo Cultural y estratégico: "[Los museos, como] las olimpíadas, son tan susceptibles de convertirse en meras políticas de imagen como de generar considerables beneficios económicos y sociales"-(Monclús, 2006).

Los beneficios que generan los museos pueden mantenerse en las zonas más turísticas o distribuirse por toda la ciudad. En este artículo se analiza el impacto de las redes policéntricas de museos: en la ciudad y el territorio. En concreto se pone en valor el papel de los Museos Industriales o Fábricas Culturales en la Provincia de Barcelona, como una buena base para reactivar y cohesionar la región. Debido a la localización, generalmente periférica de los elementos industriales, se genera una tendencia opuesta a la concentración de museos en zonas ya céntricas o como Nikolić (2011) denomina, clúster de museos. La característica que se analiza en los casos de estudio es la tendencia opuesta: la descentralización, u organización multi-nodal. Ésta permite una distribución más extensiva de los beneficios que supone la transformación cultural de tejidos obsoletos. Para 
comprobar esta característica se analizan dos casos de estudio en tres escalas diferentes, comenzando por una revisión de la situación socioeconómica de las fábricas culturales.

\section{Contexto socioeconómico de las fábricas culturales}

Diversas redes de patrimonio industrial se dedican a promover la cultura de los momentos clave de la industrialización, mostrando máquinas, elementos construidos y procesos en los lugares donde se produjeron: las fábricas. Estos espacios museísticos que aúnan patrimonio industrial con promoción cultural los denominamos en esta investigación Fábricas Culturales. Arrancamos encajando este concepto en el período histórico contemporáneo y la posición de los casos de estudio en el panorama museístico catalán.

El periodo post-industrial se caracteriza, por el declive de las actividades secundarias a favor de las terciarias y cuaternarias (Touraine, 1969; Bell, 1973). Esta época también se conoce como la Era de la Información o Era digital, ya que se basa en el desarrollo de esta tecnología, permitiendo la revolución en la comunicación y dando lugar a la explosión de los mass media o medios de comunicación masivos. La educación, la creatividad o el conocimiento, en suma los productos culturales, cobran mayor importancia y se democratizan, llegando a un mayor número de personas. A su vez la población mundial se dispara y se traslada a las ciudades en un fuerte éxodo rural. Nacen las ciudades globales, las metrópolis contemporáneas, o incluso las megalópolis de más de 10 millones de habitantes. En este ritmo frenético es importante detenerse y replantear cuál es el sentido de la cultura, sobretodo en ámbitos locales; cómo influyen en ella las constantes corrientes migratorias y cómo se traduce todo ello en el diseño de la ciudad.

Los museos, junto con otros centros culturales, cumplen un rol imprescindible como lugar de encuentro y reflexión. A estos espacios se les supone una capacidad transformadora o soft power (Lord y Blankenberg, 2015) que se aplica a muchos niveles. Por ejemplo, "desde los años 80, [...] la conversión de la Estación d'Orsay en museo provocó una saludable toma de conciencia acerca del valor del patrimonio del siglo XIX" (Bergeron, 1996). Así surgieron diferentes museos como la Tate, de Londres, que aprovechan hitos en desuso de la ciudad para su reconversión en la nueva industria cultural. El caso de las fábricas culturales va un paso más allá reforzando el componente social y de empoderamiento local, al mostrar la historia del lugar como nuevo eje dinamizador. Al combinar contenido y continente, se refuerza la identidad local haciéndola atractiva, incluso para visitantes externos. En la mayoría de casos, además, contribuye a reactivar el entorno, generando una reacción en cadena de preservación del patrimonio construido y de promoción de la cultura industrial local. Todo ello responde al objetivo máximo de los museos ya desde su origen: atraer y concentrar talento en la ciudad para conducirla al progreso, desde Alejandría, hasta París, Moscú o Londres.

La numerosa atracción de talento, eventos y turismo reciente en Barcelona, forma parte de una política de promoción cultural en la que los museos y elementos patrimoniales tienen un gran peso. De hecho, "los museos de Cataluña ocupan la sexta posición por visitantes de Europa"1. Sin embargo este éxito no es homogéneo, solo 12 de los 776 centros patrimoniales catalanes concentran el $71 \%$ de las visitas 2 . A esto se suma el desequilibrio territorial, ya que la región metropolitana de Barcelona atrae al $80 \%$ de los visitantes ${ }^{3}$. Por ello se buscan nuevas fórmulas para la redistribución de los visitantes, y con ello de los núcleos creativos, por áreas cada vez más extensas. Para ello se plantean redes descentralizadas de museos, tanto a nivel temático como territorial $^{5}$. Esto permite además promover buenos ejemplos entre los centros mayores o más experimentados y los menores o más recientes.

${ }_{1}^{1}$ Geli, C. (30 Julio 2015) “Museos catalanes: tenemos un plan” [en línea]. El país digital. <http://ccaa.elpais.com/ccaa/ 2015/07/30/catalunya/1438290994_601945.html>, [16 Abril 2017].

2 Montañés, J. A. (12 Febrero 2017) “Los visitantes de los museos, a examen” [en línea]. El país digital. <http:// ccaa.elpais.com/ccaa/2017/02/12/catalunya/1486927619_712334.html> [16 Abril 2017].

${ }^{3}$ Playà Maset, J. (9 Febrero 2017) “Desequilibrios entre los museos catalanes” [en línea]. El país digital. <http:// www.lavanguardia.com/cultura/20170209/414168015298/desequilibrios-museos-catalanes.html> [16 Abril 2017]. 
Casos pioneros en la construcción de estas redes descentralizadas son el Museo de la Ciencia y la Técnica de Cataluña (mNACTEC) y el Museo de Historia de Barcelona (MUHBA). Ambos tienen diferentes sedes, que frente a la tendencia de concentrar los centros museísticos en torno a una única calle, o isla de museos, generan redes de centros esparcidos por el territorio. En el caso del mNACTEC los museos se ubican en toda Cataluña, mientras el MUHBA se ubica en la capital. Como vemos en las siguientes tablas ${ }^{4}$, la sede del mNACTEC es el museo más visitado fuera de la capital. En el caso del MUHBA es el sexto más visitado en la capital. Ambos museos tienen en común no solo la dilatada y exitosa trayectoria, sino también la reutilización de Patrimonio Industrial. Los elementos integrantes del sistema territorial del mNACTEC son todos Fábricas Culturales, mientras que el MUHBA está formado también por conjuntos patrimoniales de épocas diferentes. Nuestro objetivo es mostrar en qué medida estas redes suponen una tendencia innovadora, frente a la centralidad de servicios, contribuyendo a la generación de nuevas conexiones y zonas dinamizadas culturalmente a pesar de su posición no tan central.

VISITANTS ALS PRINCIPALS LLOCS D'INTERÈS

VISITANTES A LOS PRINCIPALES LUGARES DE INTERÉS VISITORS TO MAIN PLACES OF INTEREST

Top 10 Museus i col·leccions

Top 10 Museos y colecciones

Top 10 Museums and collections

\begin{tabular}{|c|c|c|c|}
\hline & & 2014 & 2015 \\
\hline 1 & $\begin{array}{l}\text { Museu de la Ciència i la Tècnica (MNACTEC) - } \\
\text { Seu Terrassa* }\end{array}$ & 88.409 & 104.403 \\
\hline 2 & Museu del Cau Ferrat - Sitges & 19.409 & 99.802 \\
\hline 3 & Museu de Maricel - Sitges & 34.585 & 76.790 \\
\hline 4 & Museu de Badalona & 66.170 & 71.464 \\
\hline 5 & Museu de Terrassa & 62.665 & 65.635 \\
\hline 6 & Museu de Gavà - Parc Arqueològic de les Mines & 53.850 & 52.697 \\
\hline 7 & Museu de la Pell d'Igualada i Comarcal de l'Anoia & 63.037 & 49.617 \\
\hline 8 & Museu Molí Paperer de Capellades & 36.531 & 43.482 \\
\hline 9 & Museus de Sant Cugat & 42.769 & 40.989 \\
\hline & $\begin{array}{l}\text { Museu Torre Balldovina - Santa Coloma de } \\
\text { Gramenet }\end{array}$ & 34.645 & 38.197 \\
\hline & Total Top 10 & 502.070 & 643.076 \\
\hline
\end{tabular}

Museu que no forma part de la Xarxa de Museus Locals de la Diputació de Barcelona Museo que no forma parte de la Red de Museos Locales de la Diputació de Barcelona Museum that are not part of the Local Museums Network of Barcelana Provincial Council
VISITANTS ALS PRINCIPALS LLOCS D'INTERÈS

VISITANTES A LOS PRINCIPALES LUGARES DE INTERÉS VISITORS TO MAIN PLACES OF INTEREST

\section{Descentralización territorial, mNACTEC}

Las redes de Fábricas Cultuales son herramientas que, más allá de mostrar pruebas fehacientes de lo que significó un determinado momento histórico en su territorio, promueven la coordinación y el intercambio cultural. Sus centros ponen en valor el patrimonio y la ciencia, como herramientas de desarrollo local. Para comprender mejor su funcionamiento, estudiamos el mNACTEC por su proximidad y cualidades innovadoras. Las fuentes principales para desarrollar este apartado son las publicaciones (Casanelles 2007, 2013) y entrevistas a Eusebi Casanelles, director del mNACTEC en el momento de su fundación. Primero establecemos la relación temporal con otras redes patrimoniales a nivel internacional, a continuación explicamos las características innovadoras del sistema territorial del mNACTEC y su gestión. Siguiendo un orden cronológico, destacamos 6 fechas relevantes para este estudio:

- 1967 - Se crea la primera red de espacios patrimoniales del periodo industrial: Ironbridge Gorge Museum Trust formado por 35 espacios históricos, 10 de ellos museos.

- 1978 - Nacimiento del TICCIH o Comité Internacional para la Conservación del Patrimonio Industrial, con motivo de la III Conferencia Internacional sobre la Conservación de Monumentos Industriales que se celebra en Suecia.

\footnotetext{
${ }^{4}$ Ajuntament de Barcelona. "2015 - Estadístiques de turisme. Barcelona: ciutat i entorn. Estadísticas de turismo. Barcelona: ciudad y entorno Tourism statistics. Barcelona: city and surroundings"
} 
- 1980 - El TICCIH se configura como consultor de la UNESCO para la selección de los monumentos, sitios y paisajes de la industria y de la industrialización y así incluirlos en la lista del Patrimonio.

- 1990 - El mNACTEC se establece como Museo Nacional y por tanto siguiendo la ley de museos del mismo año, vincula la exposición de piezas patrimoniales con el mantenimiento de espacios de interés, a lo largo de todo el país. Junto a diferentes profesionales del sector seleccionan 75 elementos del Patrimonio Industrial Catalán, listado que se amplía en varias ocasiones hasta los 150 elementos con los que cuenta en la actualidad.

- 1999 - ERIH, la Red Europea de Patrimonio Industrial, promueve y difunde diferentes redes de patrimonio, incluyendo nuevos recorridos temáticos internacionales. Cuenta con más de 1.300 espacios en 45 países.

- 2011 - TICCIH España elabora el estudio, exposición y publicación de 100 Elementos del Patrimonio Industrial en España.

Analizando la evolución del patrimonio industrial podemos observar ventajas e inconvenientes de su organización en red. En primer lugar, sus elementos se vinculan fuertemente al territorio, por lo que se presta a su explicación descentralizada, localizada allí donde los recursos eran propicios para el desarrollo industrial. Si bien su encaje en red favorece la continua adhesión de elementos, es necesario cierto criterio que cohesione el sistema. Por otra parte, estas estrategias de reconversión cultural deben acompañarse de otras de participación local para un impacto óptimo en el empoderamiento de sus comunidades.

No es de extrañar que la red más antigua de Espacios Patrimoniales Industriales coincida con el lugar considerado la cuna de la industrialización: la zona del Ironbridge, o puente de hierro. Su temprana recuperación en 1967 le permite contar con numerosos testimonios del arranque de la industrialización. Esta propiedad patrimonial de $5.5 \mathrm{Km}$ se convierte, tras haber sido un referente arquitectónico e industrial en sus inicios, en un referente museístico, por su reconversión. Hoy en día sigue ayudando a expandir su modelo con guías sobre cómo hacer un espacio patrimonial sostenible, económicamente enfocado al turismo, o cómo interpretar los recursos para que lleguen mejor al público. Además, este caso es singular, no solo por su sistema en red, o su gestión como ONG, sino por la apuesta de la pervivencia de las actividades asociadas al lugar. Así se mantiene vivo el relato de lo que sucede en ese territorio, como parte fundamental de la experiencia.

Un caso similar sucede en Cataluña, donde la preocupación y conservación por el patrimonio industrial es anterior a la formación del mNACTEC. Uno de los primeros ejemplos, de lo que hoy llamaríamos arqueología industrial, lo encontramos en el Museu Molí Paperer de Capellades, fundado en 1958. Este antiguo molino de $2.200 \mathrm{~m}$, a $60 \mathrm{~km}$ de Barcelona, recibe el respaldo de industriales del papel para su recuperación y reconversión en museo. Posteriormente acaba formando parte del sistema territorial del mNACTEC, reforzando su identidad y aportando un elemento fundamental para el conjunto de la red. El museo gana relevancia con su reconocimiento "nacional", como museo molinero, y el sistema se beneficia al contar con la experiencia de un centro pionero en la recuperación del patrimonio industrial. Además su proximidad a Igualada permite la comparación histórica entre una población movida por el papel y otra por la piel.

La principal característica actual de este espacio es su diversidad funcional, lo que le permite una mayor independencia económica. "El Museo Molí Paperer de Capellades es un museo atípico, tanto por la dualidad museo-molino como por su sistema de gestión económica, que logra la autofinanciación del $60-70 \%$ de los gastos de funcionamiento" 5 . Más allá de museo, sigue trabajando el papel con numerosos talleres, cursos, y hasta una tienda de materias primas y tratadas, vinculadas al papel. Todo ello lo ratifica como fábrica cultural, o lugar que mantiene la historia viva de la industrialización, mientras continúa generando nuevos contenidos y promoviendo la creatividad.

Posteriormente, en 1978, el TICCIH o Comité Internacional para la Conservación del Patrimonio Industrial aparece como reflejo del interés de diferentes países por dar a conocer sus lugares 
emblemáticos en torno a este momento histórico y compartir esfuerzos o estrategias destinados a su conservación. España forma parte del TICCIH, con una fuerte vinculación del 2000 al 2009, por ser el director de la red internacional Eusebi Casanelles, fundador del mNACTEC. El reconocimiento a este Comité llega de la mano de la UNESCO en 1980, al formar parte de su grupo de consultores de Patrimonio.

La tesis Économuséologie: comment rentabiliser une entreprise culturelle de Cyril Simard (1989), incide en la aparición, tres años más tarde, de una red canadiense que convierte talleres artesanos en Economuseos. Actualmente este ejemplo se ha extendido a todo el mundo, ganando un importante reconocimiento y dando lugar a movimientos similares. La clave de este éxito reside probablemente en la apuesta por tender puentes entre el pasado y el futuro, promoviendo el diálogo entre productores y consumidores.

En cuanto al territorio Europeo, la red ERIH, surgida en 1999, destaca por encima del resto en su misión aglutinadora y generadora de sinergias en el ámbito del Patrimonio Industrial. La propia organización explica la Revolución Industrial como un proceso posible gracias a sus redes, desde el principio internacionales, que facilitan el intercambio de bienes e ideas: "Desde mediados del siglo XVIII, nuevas tecnologías y métodos de producción se extendieron rápidamente por Europa. Los productores construían sus fábricas en diferentes países y generaban grandes beneficios, mientras miles de trabajadores migraban a las emergentes áreas industriales. Uniones de comercio lucharon exitosamente por los derechos de los trabajadores, los cuales se filtraron en el estado del bienestar Europeo actual" (Meinrad, 2016).

Entender las sinergias generadas en estos territorios es parte indisoluble de la historia Europea y como tal, merece ser conservada. Así lo entiende la Unión Europea, con diferentes ayudas a esta organización y una participación importante de la misma en los eventos del 2018, Año Europeo del Patrimonio Cultural. La principal herramienta del ERIH es su web, donde promueven diferentes rutas tanto locales como internacionales, así como las diferentes reuniones y conferencias que facilitan el intercambio de buenas prácticas. Una de sus citas destacadas, es la del agricultor Arthur Young de 1789, tras el derribo de la Bastilla, "mucho más poderosas son las cosas que las palabras". Al igual que las redes anteriores, parte de su éxito reside en el reconocimiento del poder potencial de los espacios patrimoniales: "Las comunidades industriales buscan diferentes direcciones [futuras] siendo conscientes de que el nuevo crecimiento podría obtener beneficios de sus raíces en el pasado" (Meinrad, 2016).

Con anterioridad a la red Europea, se crea en Cataluña el Sistema Territorial del museo Nacional de la Ciencia y la Técnica. Su origen se remonta a 1981, cuando el Departamento de Cultura de la Generalitat de Cataluña encarga el proyecto para este museo. Desde su origen "el propósito era hacer una estructura innovadora respecto a las que había y que fuera un referente de la museología técnica a nivel europeo" (Casanelles, 2007, p.5). Concretamente en 1990, fruto de las influencias internacionales y de las características locales del territorio, se crea esta red, diferente del resto por su mixtura de componentes innovadores, los más destacados (Casanelles, 2007, p.9):

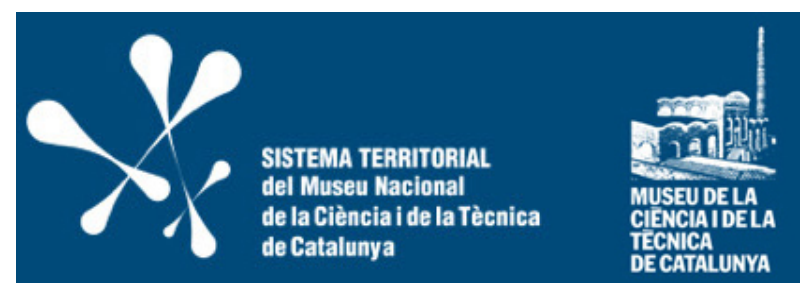

- Descentralización y atención al territorio.

- Biodiversidad, geo-diversidad, tecno-diversidad y socio-diversidad.

- Complejidad, modernidad y fomento de la creatividad.

Figura 2. Logo del sistema y de la sede.

Fuente: http://sistema.mnactec.cat/ [4 ago. 2017].

El primer factor está relacionado con su carácter descentralizado y por tanto de red. Este factor surge a consecuencia del segundo, la diversidad de la zona y la presencia de algunos espacios ya musealizados desde hace años, como el Museo de la Piel de Igualada (1954), o el Molino Papelero (1958) ya mencionados. Todos estos espacios se influencian mutuamente, permitiendo su unión en redes cada vez más complejas. Esta característica surge de las premisas iniciales del proyecto, una gran ambición con pocos recursos. Al igual que durante la industrialización catalana, la red actual de museos de Ciencia y Técnica de Cataluña no está formada por pocos centros 
de renombre, sino por una buena gestión territorial que permite reconocer el patrimonio desplegado por toda la zona. De acuerdo con Casanelles (2013) los cuatro conceptos que guiaron el proyecto desde el inicio son:

- Un Museo Nacional al servicio de la museología catalana técnica de Catalunya.

- De un museo de ciencia y técnica a un museo de la industrialización.

- Los bienes inmuebles son bienes museísticos.

- El Museo descentralizado y la búsqueda de un modelo museístico territorial.

Este último concepto es de especial relevancia, ya que los museos nacionales catalanes siempre habían estado en Barcelona capital, hasta que en 1984 se establece el museo de la Ciencia y la Técnica de Cataluña en Terrassa y seis años después la Ley de Museos lo declara Museo Nacional. "La Ley de museos de 1990, en su prefacio dice: Los museos nacionales [Catalanes] encabezan la articulación del sistema museístico de Cataluña [...] y extienden su servicio a todo el País" (Casanelles, 2013, p.32). De hecho el lema del sistema territorial del mNACTEC es: UN MUSEU NACIONAL ESTĖS PER TOT EL PAÍS.

Podemos ver a continuación (Figura 3) la comparación entre la localización de las Instituciones Culturales Nacionales Catalanas, como la Biblioteca de Cataluña de 1914, el Museo Nacional de Arte de Catalunya de 1929, el Archivo Nacional de 1984 o el Museo de Arqueología de Cataluña de 1990, frente a las sedes del mNACTEC de la provincia de Barcelona. Se compara sobre dos mapas de Cataluña: primero el plano histórico de Rubió y Tudurí de 1932, que muestra la distribución de zonas del territorio catalán fruto de un estudio para el Regional Planning; y posteriormente un mapa reciente de las carreteras actuales, extraído del Instituto Cartográfico y Geológico de Catalunya. Ambos han sido ajustados para mostrar los límites de la provincia de Barcelona.

En los planos que sirven de base observamos cierta evolución hacia un sistema más ramificado e interconectado. La extensión de infraestructuras, así como la ubicación descentralizada de los museos son muestras de la intención de las autoridades por conectar bienes y servicios a través del territorio y difuminar los límites de la cultura más allá de la capital. Como destaca la red ERIH: desde la revolución industrial las ciudades ganan fuerza pero no lo hacen de forma independiente. Las relaciones entre ellas son simbióticas, ofreciendo ofertas variadas y beneficiándose de formas diferentes las unas de las otras. El intercambio es clave para el desarrollo industrial y lo continúa siendo en la era de la información.

Actualmente, el sistema territorial mNACTEC continúa extendiendo la cultura técnica e industrial con diferentes programas, como el reconocimiento de 150 elementos patrimoniales industriales en Cataluña, que en el 2011 se extiende, gracias a la red TICCIH España, por todo el territorio Español. Su planteamiento como red "nacional" y su adhesión a redes internacionales, le ha permitido asentarse con más fuerza y llegar más lejos. Además, a nivel demográfico, la población se mantiene o crece no solo en la capital, sino en toda la provincia, lo que denota la capacidad de atracción de jóvenes por parte de estos municipios. El mNACTEC se alinea con este objetivo, estableciéndose como un referente en visitas escolares, promoviendo el interés en la ciencia, la técnica y el patrimonio entre los más jóvenes6.

\footnotetext{
${ }^{6}$ Observatori dels Públics del Patrimoni Cultural de Catalunya. (2017) "Recompte de visitants dels equipaments patrimonials de Catalunya 2015" "Els equipaments patrimonials dedicats a la Ciència i la Tècnica són els que tenen una major atracció d'escolars amb una mitjana superior als 15.500 estudiants. Segurament derivat d'aquest fet aquests museus i coløleccions són també els que presenten una taxa més elevada d'usos per visitant $(2,37)$, molt superior a la resta d'equipaments."
} 

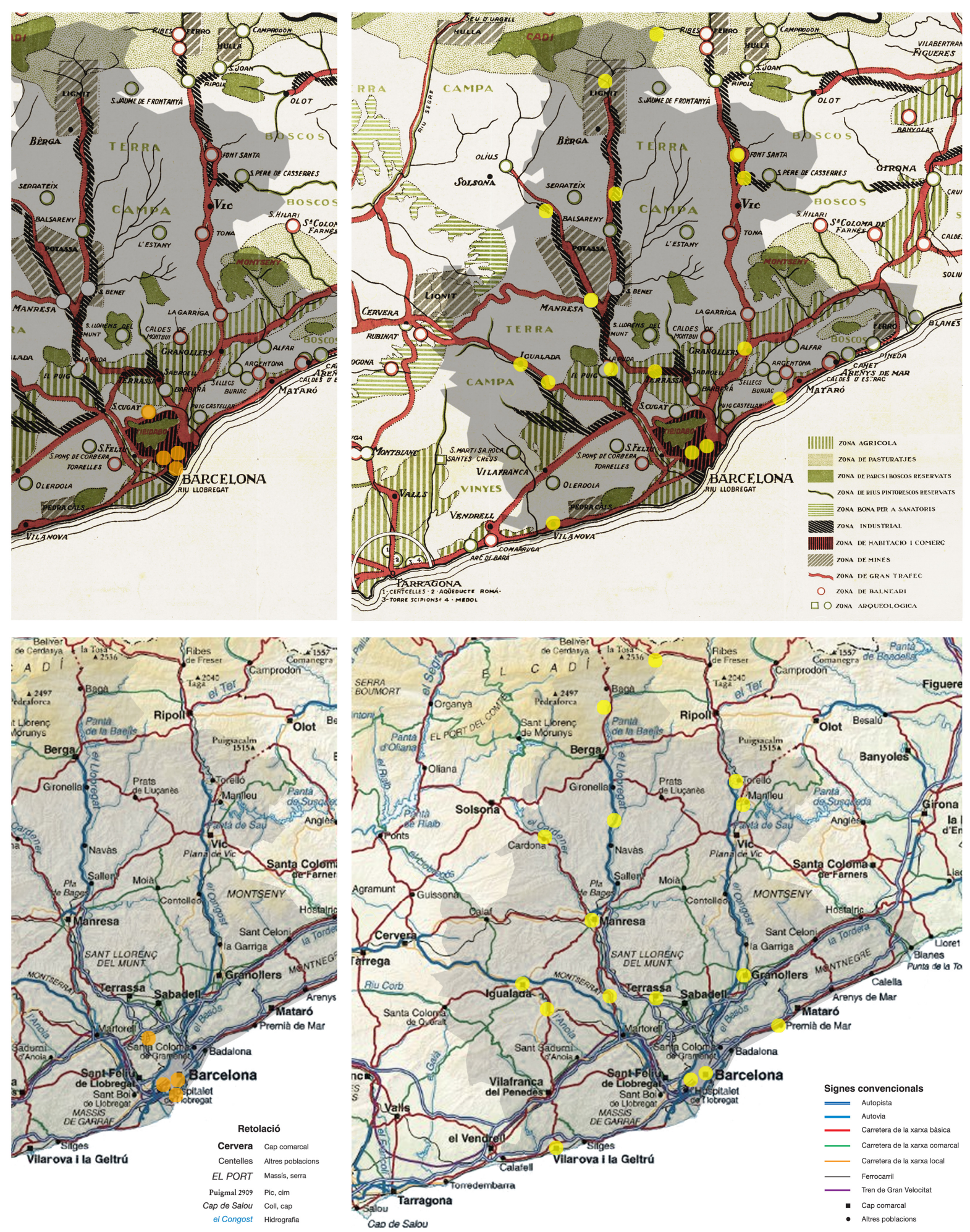

Figura 3. Elaboración propia en base a mapas de Catalunya (Rubió y Tudurí, 1932 y actual). Fuente: ICGC. 


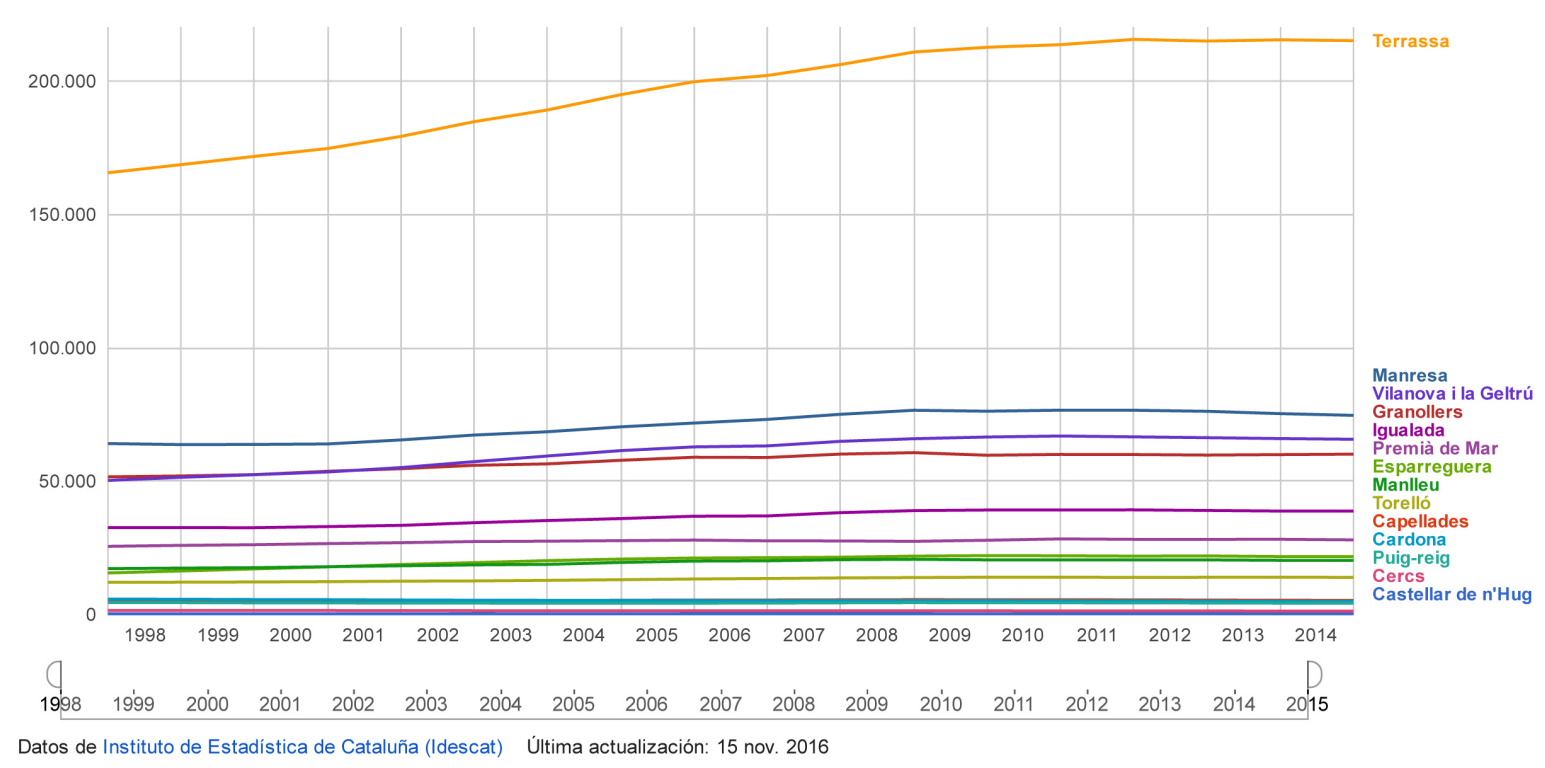

Gráfico 1. Evolución de la población en los municipios de la provincia de Barcelona con mNACTEC. Fuente: Google Public Data Explorer.

La gestión de la red del mNACTEC favorece el intercambio de ideas entre sus centros. El sistema territorial se define en referencia a otros sistemas naturales de sobra conocidos, como el solar o el circulatorio. En ellos diferentes elementos de diferentes tamaños cumplen funciones específicas, si bien todos se relacionan a través de unas leyes generales, que permiten la unión, a la vez que favorecen la independencia ${ }^{12}$. En el sistema territorial del mNACTEC ciertos miembros tienen más responsabilidades, por tanto, tiene la peculiaridad de situarse entre la asociación equitativa y la organización jerárquica. Todo ello le ha permitido crecer en el número de centros y visitantes a lo largo de sus casi 30 años de existencia. Si bien este crecimiento no es aleatorio, el sistema valora muchas características antes de acoger un nuevo miembro: la calidad y representatividad del periodo al que pertenece, así como adecuación y complementariedad del programa respecto a los miembros que ya conforman el conjunto.

Las relaciones entre los centros del sistema territorial del mNACTEC es variable en función de la temática, la propiedad o tamaño del centro y la proximidad entre los mismos. En la próxima página vemos dos diagramas propios con el tipo de centros que forman el sistema (en la provincia de Barcelona), sus características y las relaciones que se establecen entre ellos. Cabe destacar una disposición no radial, con centros en poblaciones más grandes próximas a la costa y más pequeñas los ubicados en el interior.

En cuanto a los tipos de centro, se opta por una evolución del concepto de redes distribuidas como las de internet, en ellas tal como enuncia M. Castells: "nadie es el líder" (Casanelles, 2007, p.11). Para el mNACTEC se tiene en cuenta que "el liderazgo en un sistema es necesario si se quiere realizar una política de acciones transversales" (Casanelles, 2007, p.11). En el caso del mNACTEC los museos que ejercen este liderazgo se agrupan en Museos Sede y Museos Sección. Estos últimos están acreditados como museos en el registro de la Generalitat de Cataluña. Se trata del: Museu Molí Paperer de Capellades, Museu de la Pell d'Igualada i Comarcal de l'Anoia, Museu del Suro de Palafrugell, Ecomuseu Farinera de Castelló d'Empúries, Museu de les Mines de Cercs y el Museu industrial del Ter en Manlleu. Todos ellos son los encargados de coordinar el conjunto junto a los Museos Sede que son propiedad de la entidad autónoma del museo de la ciencia y la técnica: el mNACTEC de Terrassa y el Museu Colònia Sedó d'Esparraguera. El resto son museos colaboradores, recibiendo más ayudas de los centros mayores.

Las leyes que rigen este sistema se traducen en una serie de Programas comunes para todos los miembros. Existen Programas obligatorios y opcionales. En cuanto a los primeros incluye: imagen institucional y comunicación; exposición y difusión; conservación e investigación y acción educativa. Esto incluye un logo para cada sede y un formato editorial para reforzar la importancia de las publicaciones del sistema. Además cuentan con tickets y exhibiciones compartidas, así 
como con la conexión directa a través de las páginas web de los miembros del sistema. En cuanto a los programas opcionales encontramos: paisaje y rutas industriales; turismo cultural; ciencia innovación y medioambiente.

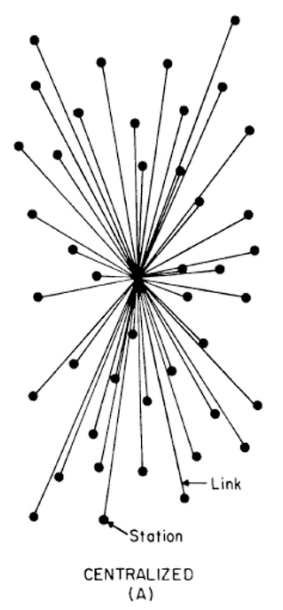

FIG. I - Centralized, Decentralized and Distributed Networks

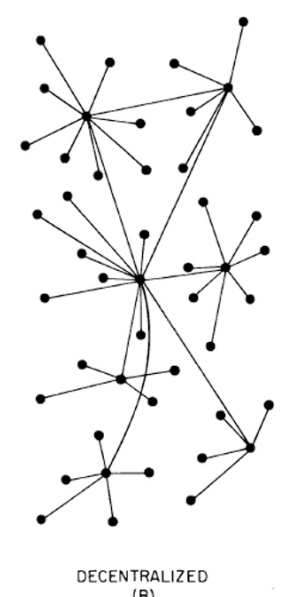

(B)

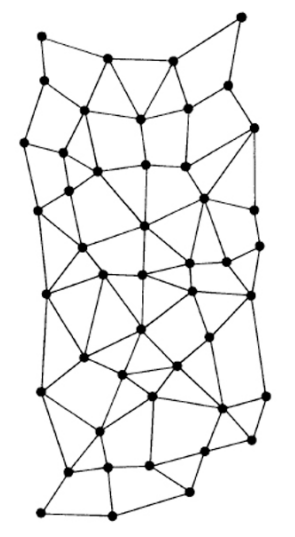

distributed Figura 4. Tipos de redes. Fuente: On Distributed Communication Networks (Baran, 1964).

Como reconocen algunos expertos internacionales "Nuestro sistema global está evolucionando de los imperios verticales integrados del siglo XIX a través de las naciones horizontales interdependientes del siglo XX, hacia la civilización en red global del siglo XXI" (Parag Khanna, 2016). Desde la industrialización las naciones intercambiaban recursos e ideas, ahora en base a las infraestructuras preexistentes se desarrollan nuevas relaciones culturales. Las ciudades comparten recursos, no de forma unidireccional, ni interconectada siempre a los mayores centros, sino de forma distribuida. En un mundo cada vez más conectado podemos devolver servicios a ciudades intermedias mediante estrategias que guíen la organización del territorio. Así como lo fueron las redes agrícolas y posteriormente las industriales, hoy en día las redes artísticas son clave para potenciar la resiliencia de las comunidades ante los retos y cambios propios de la sociedad contemporánea. En este aspecto el mNACTEC es ejemplar, por las oportunidades que brinda a sus miembros interconectados, convirtiéndolos en centros de conocimiento y creatividad. Esta red ha contribuido a dar ejemplo al territorio español, europeo e internacional, poniendo a Cataluña de nuevo en la vanguardia de la revolución, en este caso, cultural. Ver Gráficos 2 y 3.

\section{Descentralización urbana, MUHBA}

[La] extensión de la noción de Patrimonio y de su papel en la expresión de una sociedad compleja y no solo de sus élites, ha llevado a los museos de historia de la ciudad a tener muchas sedes, como fruto de una voluntad de representación amplia de los ciudadanos (Joan Roca 2015, p. 6)7.

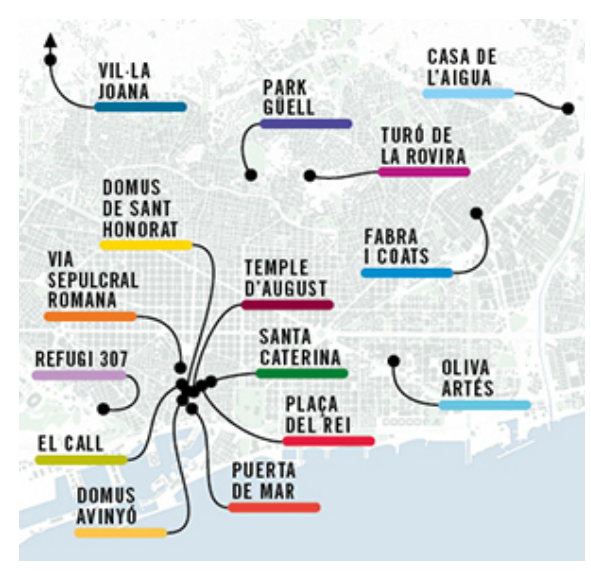

El caso del Museo de Historia de Barcelona es paradigmático, por su amplio alcance y su extensa y diversa red de espacios patrimoniales, algunos de ellos abiertos o gratuitos, incluyendo recorridos que cualquiera puede seguir. Así, toda la ciudad se con-vierte en un museo de sí misma. Contenido y continente se fusionan a un nivel máximo, hasta llegar al caso de Oliva Artés, cuyo taller sobre la calle Pere IV, mantiene el debate abierto a propuestas sobre cómo mantener y reactivar el espacio público en el que el museo se encuentra: la vía Pere IV. Sin embargo este museo no ha sido siempre así.

Figura 5. Imagen promocional de los museos del MUHBA. Fuente: http://ajuntament.barcelona.cat/museuhistoria/es/muhba-olivaartes [4 ago. 2017].

${ }^{7}$ Roca, J. (2015) JOAN ROCA. Hem de parlar. Revista Diagonal 39, p. 6. Traducción propia. 


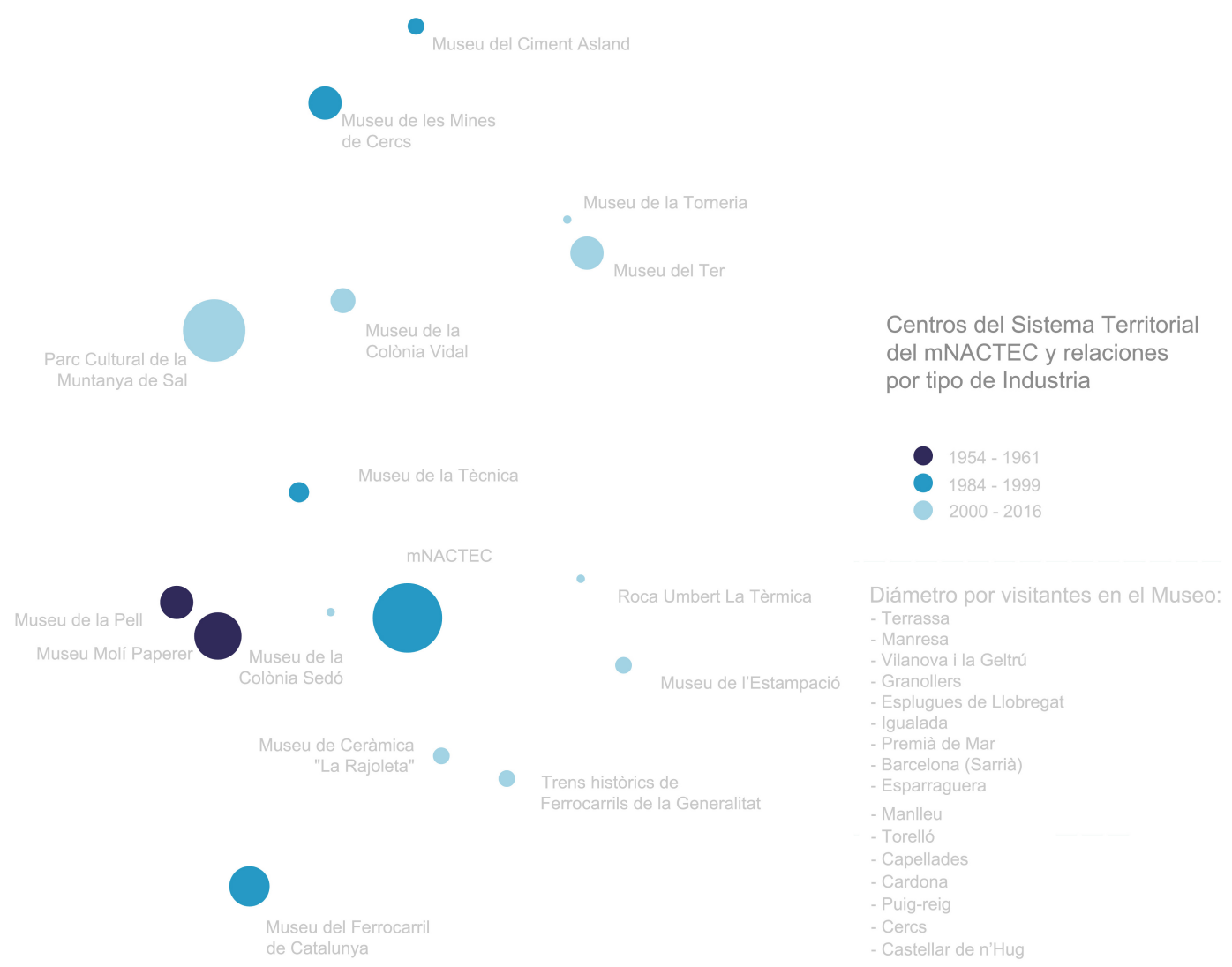

Gráficos 2 y 3. Centros del Sistema Territorial del mNACTEC en la provincia de Barcelona. Elaboración propia.

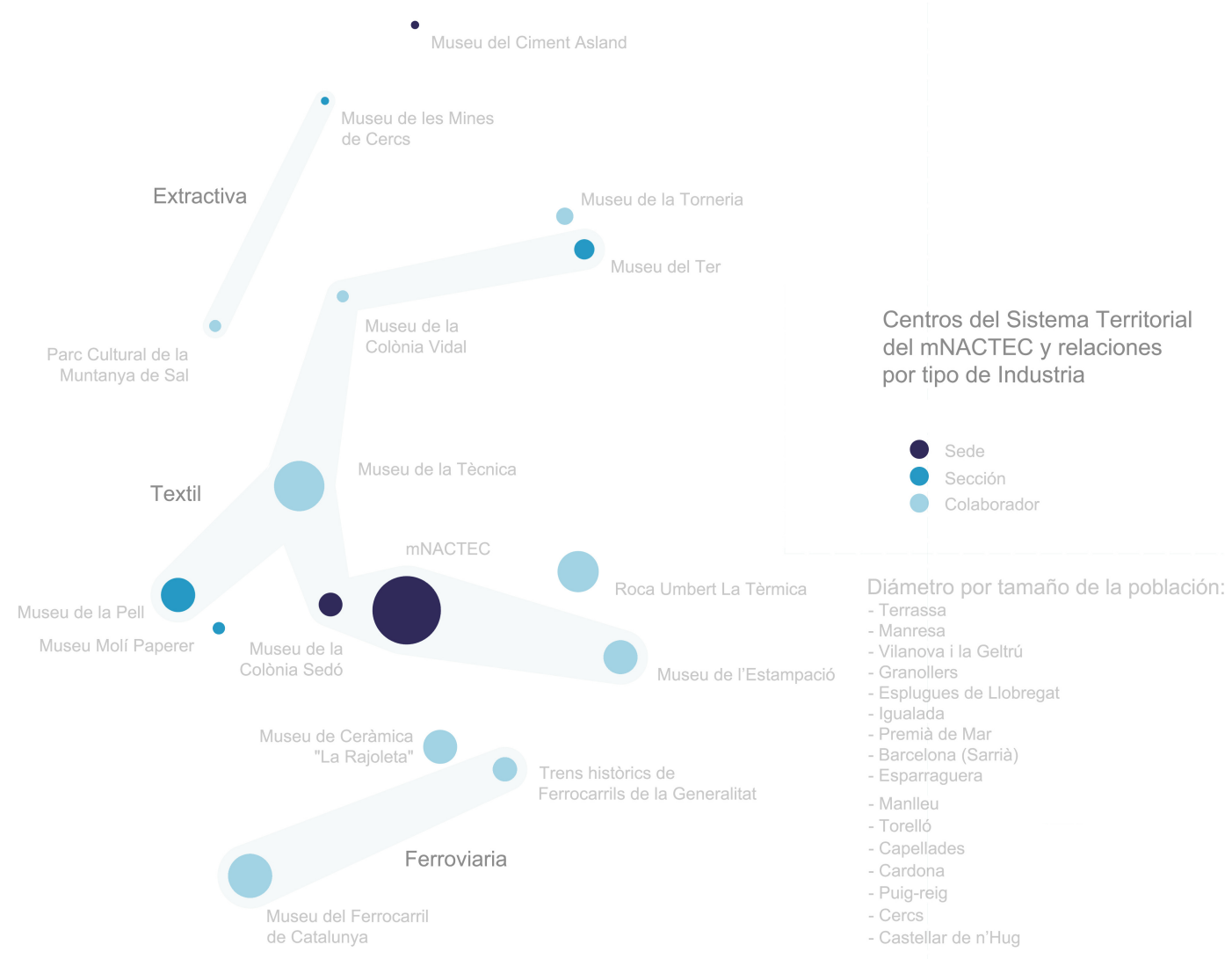


La historia del MUHBA comienza con su apertura tras la guerra civil española en 1943, si bien la idea de un museo de la ciudad se remonta tiempo atrás, hasta la exposición universal de 1888. En sus orígenes, el museo se conocía como museo de historia de la ciudad y estaba formado por sedes patrimoniales ubicadas en el casco antiguo. No es hasta el 2007, bajo la dirección de Joan Roca, que estas sedes se extienden por los barrios más jóvenes de la ciudad y su conjunto pasa a conocerse como MUHBA o Museo de Historia de Barcelona. En ese momento se inaugura la sede del mercado de Santa Catarina y progresivamente se descentraliza la ubicación de los espacios patrimoniales. Entre los más recientes destacan: el Turó de la Rovira (2011), la Casa de las Aguas (2011), Fabra y Coats (2014) y Oliva Artés (2015). Los tres últimos representan el periodo industrial y se ubican al Noreste de la ciudad, desplazando el centro de la misma.

La descentralización del relato histórico de la ciudad no pasa desapercibido si comparamos las sedes que habían en el Museo de Historia de la Ciudad (antes del 2007), frente a las que ofrece el MUHBA en la actualidad. En la página siguiente podemos ver el resultado en base a dos planos: el estudio previo de Cerdà de 1855, para el Plan del Ensanche de la ciudad y un mapa actual con los límites de los distritos municipales. En el primero destaca, como el ingeniero y visionario, que en gran medida da forma a la Barcelona contemporánea, realiza el estudio previo de la ciudad con el casco antiguo desplazado del centro. Así aprovecha las mayores oportunidades de crecimiento que ofrece la parte noreste de la ciudad, en especial, el entonces municipio de Sant Martí, que junto a otros cinco se anexionan a la ciudad en 1897. Este proceso genera una ciudad policéntrica que el MUHBA plasma mediante una red de centros conectados. Podemos comprobar en la segunda pareja de imágenes una mayor representación de distritos con sede del museo de la ciudad en la actualidad que previo a 2007: ocho a uno.

Parte del relato histórico de la ciudad es la defensa del patrimonio industrial, no como recurso para promover la ciencia y la técnica, sino como elemento fundamental de la historia de la misma. El objetivo del MUHBA es dar a conocer la importancia de la mirada histórica, junto a la científica y la artística, para comprender el mundo en el que vivimos ${ }^{8}$. De nuevo el establecimiento de una red es la seña de identidad de este conjunto de sedes patrimoniales, no solo para la propia ciudad, sino a nivel internacional. Fruto de ese esfuerzo y como parte del Plan Estratégico del Museo, en 2008 se establece la Red Europea de Museos de Historia de la Ciudad (City History Museums Network of Europe). Su objetivo es compartir y construir conjuntamente tendencias sobre actuación en el patrimonio, así como estudios de la aparición y desarrollo de las metrópolis en todo el mundo.

La organización de centros del MUHBA se define como red nucleada de centros patrimoniales. Se encuentran nodos de diferentes tipos entre los que destacan las tres sedes centrales: Plaza del Rey, Mercado del Born y la fábrica Oliva Artés. El primero relata la fundación romana de la ciudad hasta la Baja Edad Media; el segundo, la capital de Cerdà y las exposiciones (1714 a 1897); el último, de los suburbios a la metrópoli global, explica los efectos de la revolución industrial hasta la actualidad. A estos tres se incorporan otros centros "concertados" como la domus de Sant Honorat y centros de interpretación como la Fábrica Fabra y Coats.

Los programas conjuntos que organiza el museo incluyen: actividades sociales, investigación y debates, exposiciones temporales, visitas e itinerarios, educación, publicaciones y comunicación. Entre ellos destaca el museo de verano, centro para niños y niñas; el programa la belleza cura, para la tercera edad; el máster de intervención en el patrimonio y el paisaje, para universitarios; dos revistas periódicas y la web unificada con información actualizada de todos los centros. Por ultimo en colaboración con el CCCB se plantean itinerarios por toda la ciudad conocidos como: el "gran tour por Barcelona". Todos estos proyectos unificados favorecen el flujo de residentes, turistas e investigadores por los diferentes barrios de la ciudad. Si bien como vemos en el diagrama de la página siguiente, la mayor densidad de espacios patrimoniales continúa ubicándose en el centro de la ciudad, coincidiendo con la parte más antigua.

\footnotetext{
${ }^{8}$ Ayuntamiento de Barcelona, Instituto de Cultura (2008) Síntesis del nuevo Plan Estratégico del MUHBA
} 

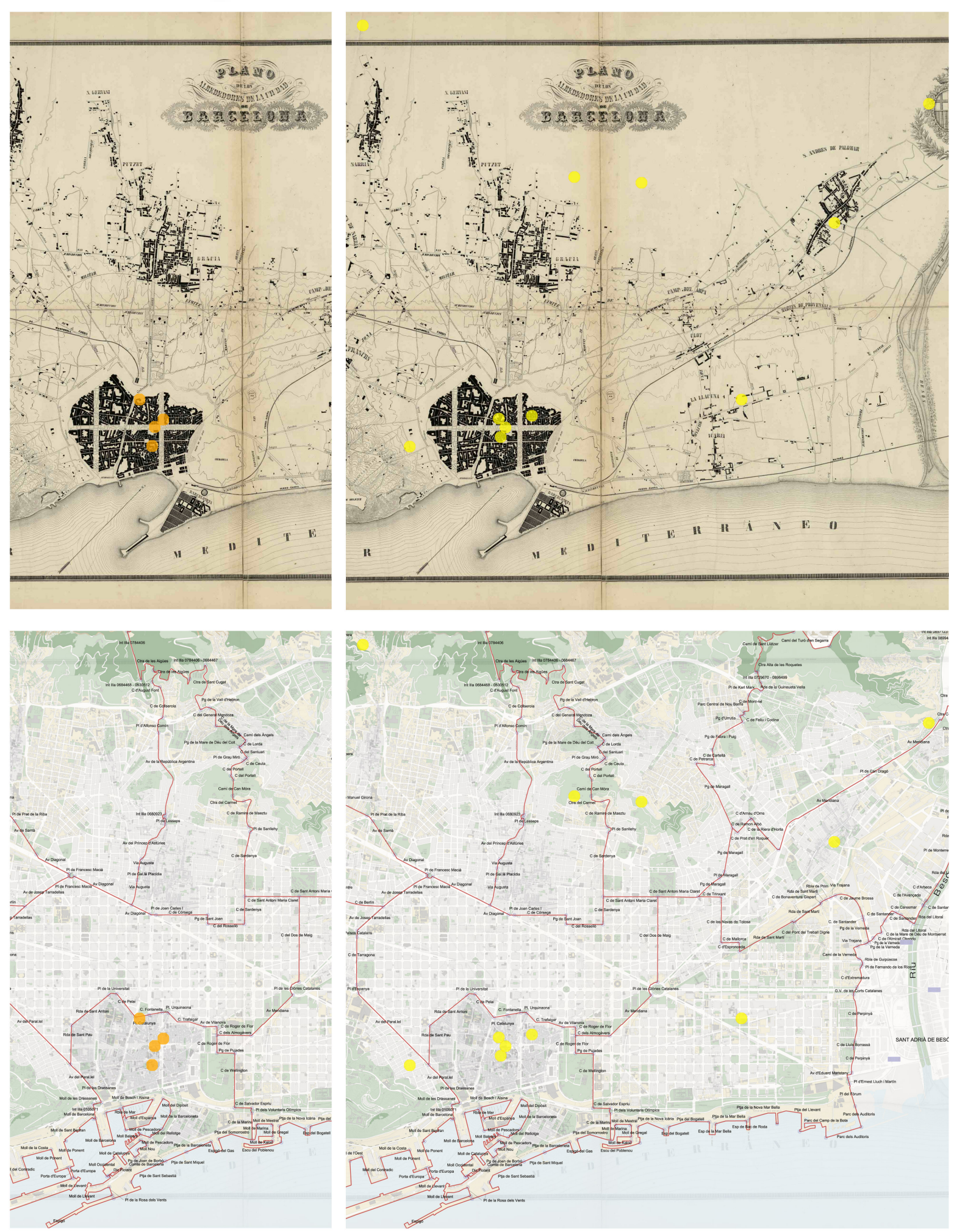

Figura 6. Elaboración propia en base a mapas de Barcelona (Cerdà, 1855 y actual).

Fuente: ICGC y IMI ${ }^{9}$.

En cualquier caso, la constitución de la red de centros distribuida por toda la ciudad, tiene efectos y objetivos secundarios beneficiosos, ya que contribuye a reconducir la presión turística y especulativa de los centros históricos de las ciudades, aportando valor a otras zonas y a su historia diversa, aún por descubrir. De esta forma se busca un cierto equilibrio entre flujos

${ }_{9}^{9}$ Descripció dels límits dels districtes municipals. Departament del Pla de la Ciutat - Direcció d’Informació de Base i Cartografia - Institut Municipal d'Informàtica (IMI) - Ajuntament de Barcelona 
migratorios y productivos, generando zonas de atracción en puntos donde aún quedan espacios libres para desarrollar nuevas empresas, grandes centros educativos o residenciales. En el caso del Poblenou, el MUHBA es un centro cultural público, que promueve talleres y encuentros entre los vecinos, para continuar el debate urbano sobre un barrio en constante transformación. En concreto la fábrica Oliva Artés se sitúa en el punto de encuentro entre dos fragmentos del 22@ un plan urbano estratégico que busca la transición de la zona de las industrias contaminantes del pasado, a las industrias culturales y tecnológicas. Además el plan es sensible frente a la reutilización de Patrimonio Industrial a lo largo del proceso, respetando la imagen y cultura industrial propia de esta parte de la ciudad. En la misma línea, el MUHBA respeta las identidades de cada barrio, a la vez que genera un hilo conductor continuo cohesionador.

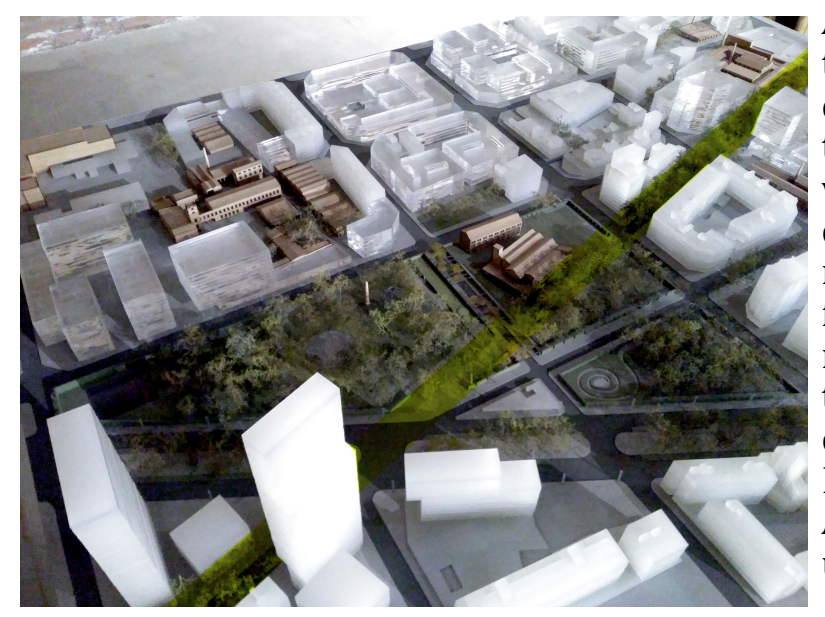

Figura 7. La vía histórica Pere IV destacada sobre la maqueta del entorno de Oliva Artés en el propio museo. En madera las fábricas del período industrial. Fuente: Captura propia.
A la fácil adaptación de los elementos industriales en nuevos usos, como el museístico, "han contribuido las mismas cualidades de la arquitectura industrial: bien situada, cerca de las vías de conexión, formando un entramado de edificios y espacios abiertos, [...] que dejan la máxima libertad de uso y capacidad de transformación" (Montaner, 2016:158). Estos factores han permitido la rápida reconversión de antiguas fábricas, en espacios artísticos de creación, incluso mucho antes de que la sede del MUHBA llegase al barrio. En este aspecto Oliva Artés viene a consolidar, más que promover, una actividad vinculada ya a la identidad de este barrio, antiguamente centro industrial de Cataluña, si bien esta tendencia no surge por parte de los organismos públicos ni privados, sino de la presión popular; en concreto, gracias a un movimiento ciudadano que investigó y reclamo la conservación de algunas fábricas para evitar el desastre de la Villa Olímpica, donde fueron totalmente arrasadas. Entre ellos se encontraba el actual director del MUHBA, Joan Roca. Una de las fábricas que se pidió y consiguió rescatar era la Oliva Artés; por lo que definitivamente este edificio cuenta en sus propias paredes la historia de su barrio, y, por tanto, parte de la historia de la ciudad.

Las fábricas de creación en el Poblenou, constituyen un ejemplo inicial del cambio de paradigma respecto a lo que podrían acabar como ruinas industriales en la ciudad. Comienzan con la apropiación de naves para espacios culturales de carácter menos público e institucional que la gestionada por el MUHBA. Estos centros se sitúan en diferentes puntos de la ciudad, con mayor presencia en Poblenou, donde cabe destacar: el Hangar, colindante a Oliva Artés; La Escocesa y la Sala Beckett/Obrador, ambas en Pere IV; o la más próxima al mar, Palo Alto, la primera fábrica reclamada del barrio, por un grupo de artistas, encabezado por Javier Mariscal, que actualmente incluye su estudio y un mercado. Todos ellos confirman una transición desde aquellos momentos en que la ciudad parecía avergonzarse de su trayectoria industrial (Tatjer, 2006), hasta la situación actual en la que se reconoce tanto su valor histórico, como su potencial social, económico y urbano.

Barcelona siempre ha apostado por operaciones culturales para incentivar la transformación de diferentes zonas de la ciudad. La idea del Barrio Gótico de Ramón Rucabado (1911), junto a las operaciones producidas por las exposiciones Universales en la Ciudadela (1988) y en Montjuic (1929), o las más recientes Olimpiadas (1992) y Fórum de las Culturas (2004), han generado imágenes de la ciudad que configuran el paisaje urbano actual10. Ahora la tarea es reconectar todos esos hitos en un relato conjunto, plagado de historias, de éxitos, de derrotas, de acontecimientos en los que las clases trabajadoras también son protagonistas. Para comprender la distribución de los centros patrimoniales del MUHBA hemos elaborado una imagen, que si comparamos con el caso anterior de descentralización territorial, nos muestra como en este caso, al combinarse patrimonio de diferentes épocas, aparecen muchos más ejemplos de la época romana

${ }^{10}$ Roca, J. (2015) Revista Diagonal 39, Entrevista, p. 6. Traducción propia.

(C) Labor \& Engenho, Campinas [SP] Brasil, v.12, n.1, p.47-70, jan./mar. 2018. 
generando más relaciones en el centro de la ciudad, que en la periferia. En este caso se realizan actividades y políticas para promover que los visitantes no se concentren sólo en una parte de la ciudad y disfruten de una oferta más variada, con actividades transversales como el ciclo de conferencias: Paisajes urbanos emergentes. Legados singulares en Barcelona (Turó de la Rovira, Casa del Agua, Oliva Artés y Plaza del Rey).

El MUHBA toma esta tarea e impulsa tanto ciclos de conferencias y reflexión dentro de los museos, como itinerarios, libres u organizados, por toda la ciudad. Sus sedes del periodo industrial, o Fábricas Culturales, contribuyen a mostrar una parte de la historia diferente de la tradicional. Mientras, las redes y otros elementos patrimoniales permiten entender la ciudad como una unidad, promoviendo la cohesión social de sus habitantes. Todo ello materializa el aforismo: el mejor museo de la ciudad, es la ciudad misma.

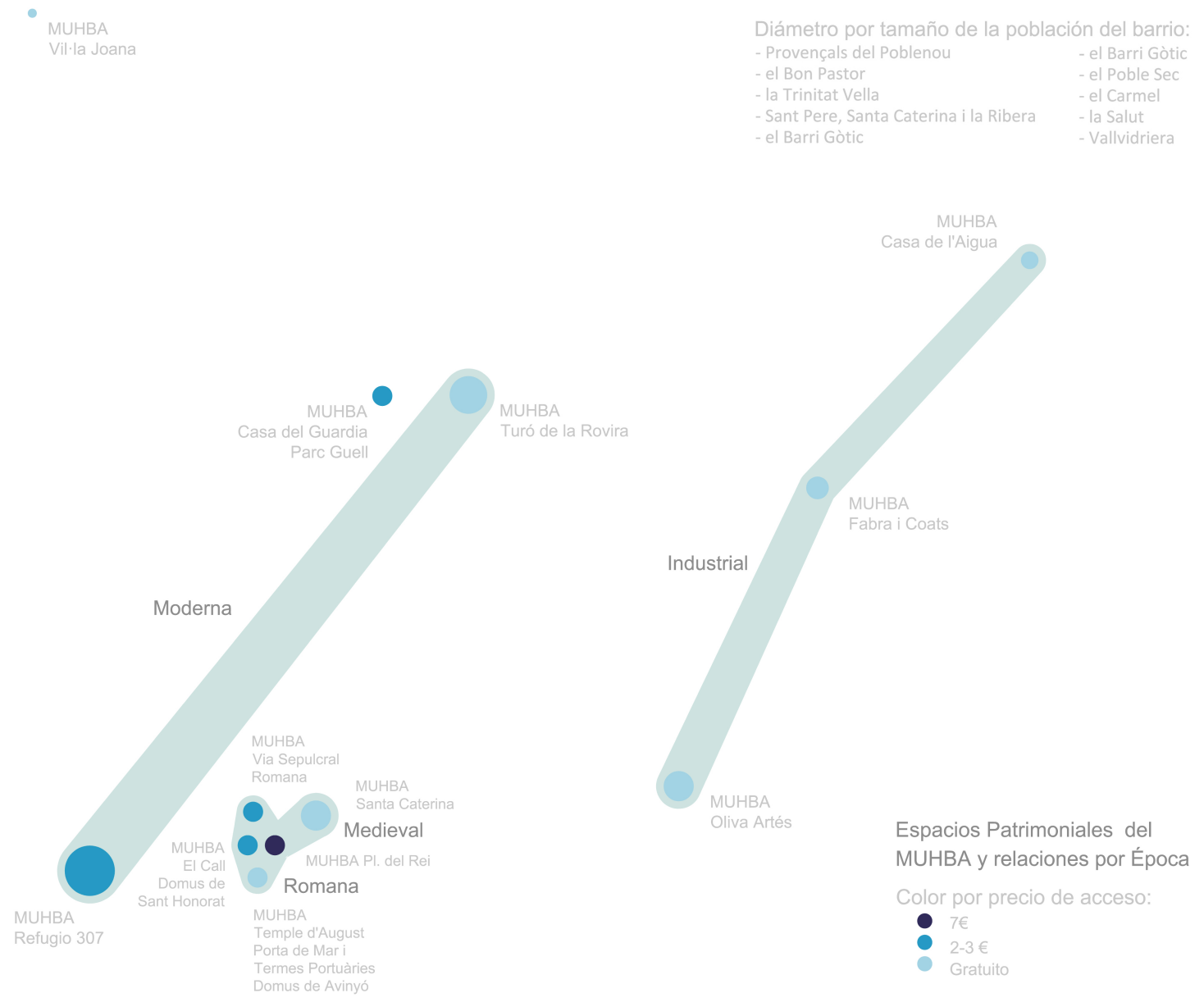

Gráfico 4. Centros del MUHBA y sus relaciones. Elaboración propia.

\section{Integración espacial de las fábricas culturales}

El museo ha salido de sus propias paredes y ha considerado todo el territorio Catalán como objeto de intervención. Gracias a este esfuerzo hecho durante los últimos 25 años, actualmente una parte notable de la sociedad admite que el patrimonio industrial es una parte del patrimonio cultural que ha contribuido a incrementar la riqueza patrimonial de nuestro país (Eusebi Casanelles 2013, p. 23).

Como menciona el impulsor del mNACTEC, el museo está difundiendo su actividad por el entorno, extendiéndola más allá de los tradicionales centros. Hemos visto las relaciones que se generan entre diferentes Fábricas Culturales a escala territorial y urbana, pero también podemos contemplar las relaciones que se generan en el entorno de los propios edificios con otros equipamientos o lugares de interés. En este caso es interesante comprobar si forman parte de la red de 
espacios públicos peatonales por ser esta una intervención urbana que permite la conexión con los centros históricos. Para ello analizamos cuatro fragmentos de espacio público: 3 del mNACTEC y 1 del MUHBA. Así, verificamos la integración del elemento en su trama.

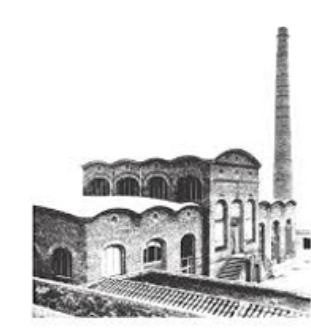

MNACTEC
SEDE

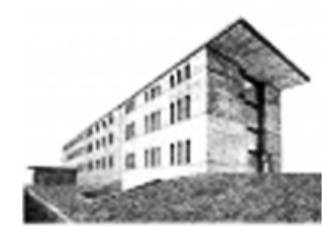

mNACTEC

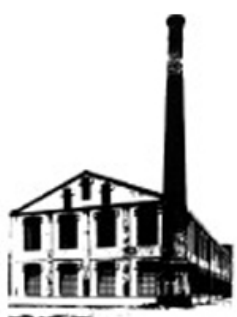

mNACTEC

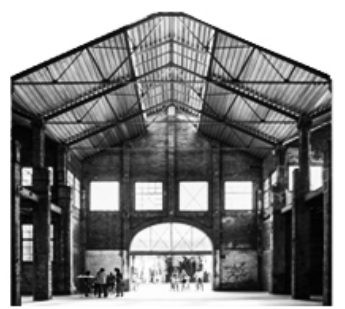

MUHBA MUSEU DEL TER MUSEU DE LA PELL DE L'ANOIA

Figura 8. Los casos objeto de estudio.

Fuente: 3 logos oficiales del mNACTEC y elaboración propia para el MUHBA.

El sistema territorial del mNACTEC ha sido pionero desde su génesis en la actuación en espacios más allá de los edificios, que cabrían en la definición más canónica de museo. Desde el inicio se han establecido criterios de protección para sus centros y guías para otros proyectos. En este sentido destacan recomendaciones del actual director del mNACTEC como "el mantenimiento de una fachada industrial, a modo de contenedor, no garantiza el mantenimiento de su originalidad y funcionalidad interior"11. También aclara los elementos a considerar en los trabajos de recuperación del patrimonio industrial (autenticidad, integridad, singularidad material, el concepto de paisaje y conjunto industrial) y los diferentes criterios de intervención: conservación de chimeneas como testimonio aislado, creación de cajas contenedor donde solo se conserva la fachada, conservación simbólica de un elemento que formaba parte de un gran conjunto o paisaje industrial, intervenciones con cambios sustanciales, intervenciones con añadidos nuevos, intervenciones de consolidación y limpieza sin añadir nuevos elementos, o no intervención.

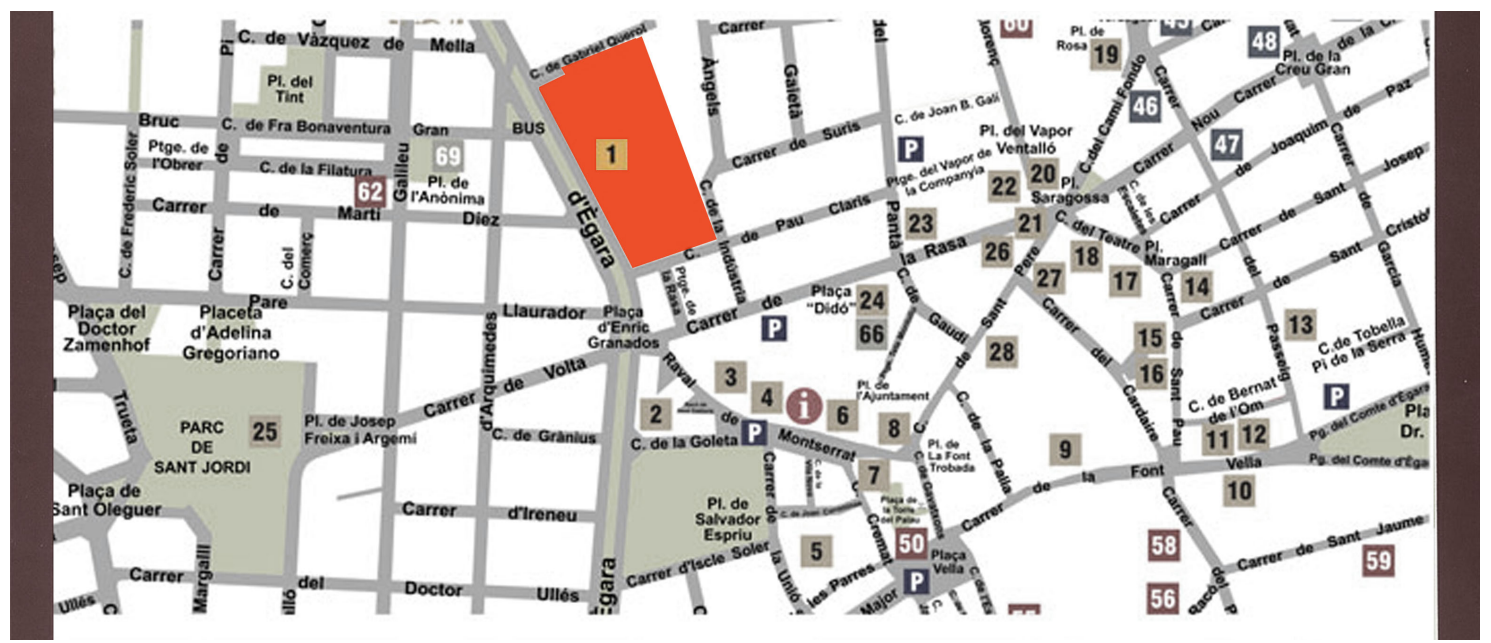

Figura 9. La sede del mNACTEC destacada sobre plano de los puntos más interesantes del modernismo en Terrassa. Fuente: Ayuntamiento Terrassa ${ }^{12}$.

Los objetivos del mNACTEC pasan por "definir los paisajes industriales de Cataluña, fomentar la conservación y actuar museísticamente a través de centros de interpretación" (Casanelles, 2013:60). Por tanto no es de extrañar que su sede central se sitúe en Terrassa. Esta ciudad es

11 Perarnau i Llorens, J. (2014) “Tot s’hi val en la recuperació del patrimoni industrial?” Revista Dovella Núm. 114 (p. 19-23)

12 http://visitaterrassa.cat/wp-content/themes/newstone/pdf/ruta_industrial_i_modernistavdjulil.pdf [28 abr. 2017]

(C) Labor \& Engenho, Campinas [SP] Brasil, v.12, n.1, p.47-70, jan./mar. 2018. 
clave para la industrialización catalana. Además el edificio seleccionado, "el Vapor Aymerich, Amat y Jover, es la fábrica textil que mejor representa la obra arquitectónica industrial modernista del país y una de las fábricas más bonitas del mundo" (Casanelles, 2013:90). Por su belleza y tamaño, su imagen se ha utilizado para ilustrar muchos libros de patrimonio industrial (Pardo Abad, 2016).

La Figura 9 muestra el entorno de la sede del mNACTEC y otros puntos de interés de Terrassa. Todos ellos forman una ruta, en la que el punto de partida es la propia fábrica. A continuación vemos uno de los planos elaborados para mostrar la relación con los espacios abiertos o singulares más próximos a los casos de estudio. Los equipamientos aparecen en rojo, las plazas en negro, las vías rodadas en un tono claro y las peatonales en uno intermedio. En este caso podemos comprobar cómo los 11.000 metros cuadrados de superficie del Vapor Aymerich, Amat y Jover tienen una fuerte presencia en su entorno. Además la sede conecta con otros puntos de la ciudad por la Rambla de Egara, un trazado histórico que comunica los límites de la ciudad de Norte a Sur. En esa vía encontramos a tan solo 600 metros, dos estaciones de tren. En la misma también se encuentra el Mercado de la Independencia, un pequeño Centro Cultural y dos plazas. El Ayuntamiento queda en la parte sudeste, abierto a una plaza posterior y rodeado por espacios peatonales que delimitan el centro. La parte trasera del museo no forma parte de esa red peatonal. El museo conecta con la ciudad solo por la Rambla, si bien frente al acceso se ha peatonalizado parte de la calle perpendicular que conecta con dos plazas. Además los accesos al museo se retiran parcialmente del linde de la Rambla, generando espacios intersticiales de reunión; pequeños pasos para promover esta zona, cargada de patrimonio.

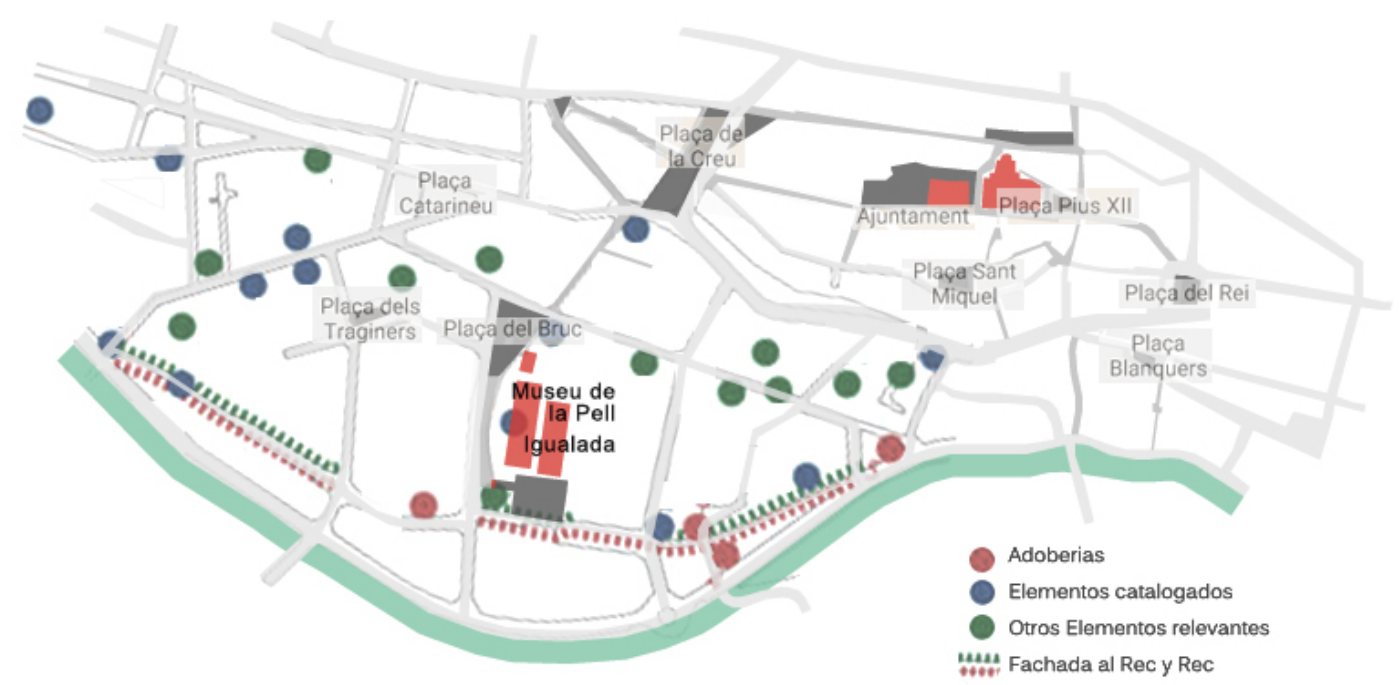

Gráfico 5. Equipamientos y espacios públicos del entorno del mNACTEC. Elaboración propia sobre fotoplano 1940 destacando fábricas que se mantienen en la actualidad (Argemi, 2014, p. 62).

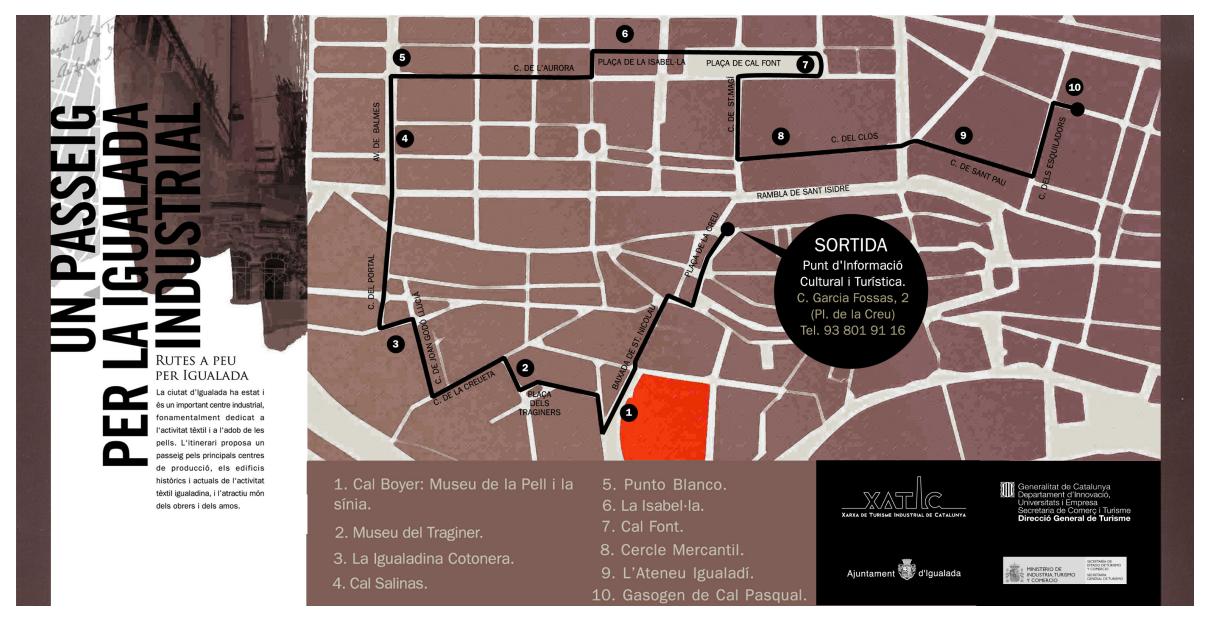

Figura 10. Museo de la Piel destacado sobre el recorrido por la igualada industrial. Fuente: Ayuntamiento de Igualada ${ }^{13}$.

13 "Paseo por la Igualada Industrial (rutas a pie por Igualada)" de la web de turismo del Ayuntamiento de Igualada. http://www.igualadaturisme.cat/turvisit.php [28 abr. 2017] 
En Igualada encontramos el Museo de la Piel y comarcal de la Anoia. Su acceso se hace principalmente desde el Norte, donde se encuentra el casco antiguo, las nuevas urbanizaciones y la estación. Desde la plaza del Ayuntamiento hacía el Oeste encontramos la plaza de la Cruz de Igualada. Desde esta hacía el Sur, una plaza triangular nos encamina a un acceso a esta sede del Museo de la Ciencia y la Técnica. El conjunto está formado por dos naves paralelas, las del antiguo complejo fabril de Cal Boyer, o Vapor Nou. Al final de una de ellas encontramos una magnífica chimenea, que da paso a un espacio abierto, semipúblico, ya que está cerrado en el mismo recinto que el museo. Del centro parten recorridos para descubrir las adoberías, una de las cuales (Cal Granotas) forma parte del museo. Si bien su visita se realiza con guía y bajo demanda, se trata de una experiencia que permite mantener en el tiempo la historia de este pueblo, que al diversificar su actividad comienza a convertirse en ciudad. En la imagen inferior vemos el tejido irregular que indica un terreno con ciertos desniveles y diferentes épocas de crecimiento. Partiendo del casco histórico hacía el río, atravesamos el barrio de las adoberías, donde se ubica el museo de la Piel. Su posición es estratégica por situarse tan próximo al río. Actualmente el barrio está empezando su recuperación como zona cultural. La calle y canal del Rec, son sinónimo de cultura; si bien muchas fábricas siguen esperando que las devuelvan a la vida.

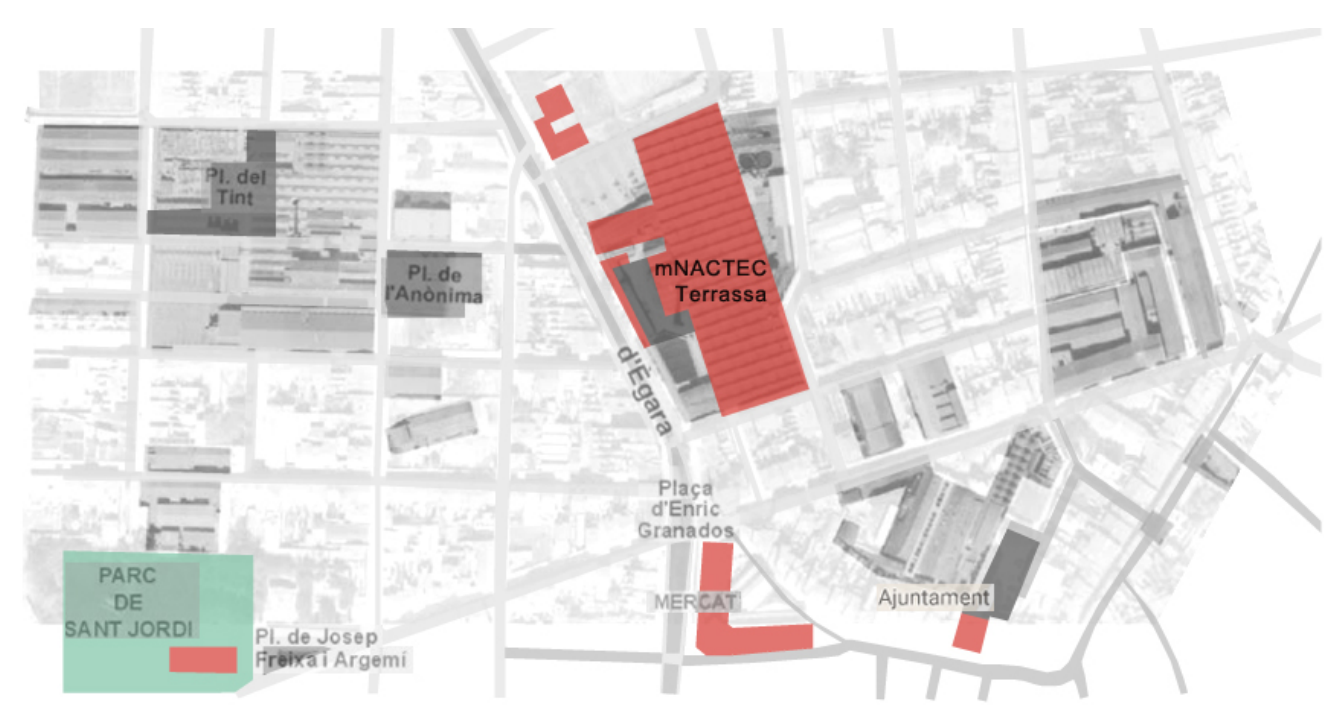

Gráfico 6. Equipamientos y espacios públicos del entorno del Museo de la Piel. Elaboración propia sobre plano de patrimonio de Amics del Rec ${ }^{14}$.

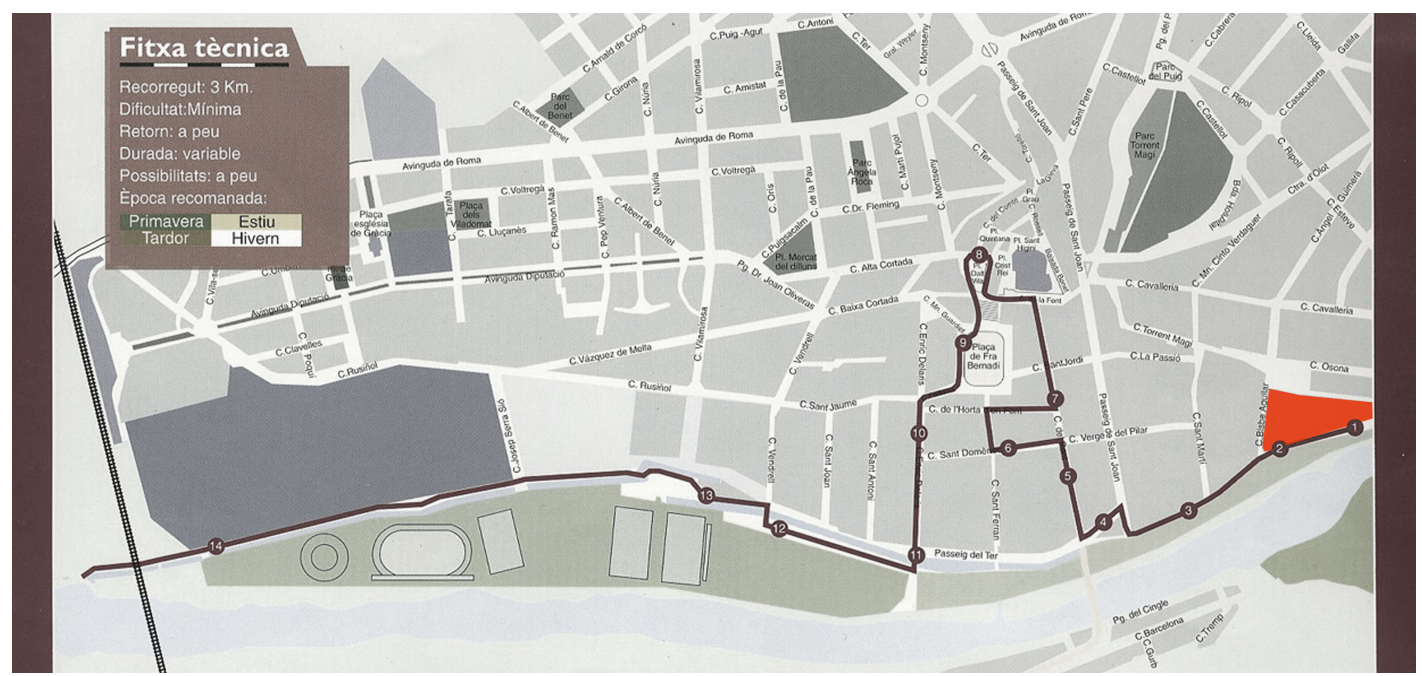

Figura 11. Museo del Ter destacado en la ruta por Manlleu. Fuente: Ayuntamiento de Manlleu15.

\footnotetext{
${ }^{14}$ http://www.amicsdelrec.org/category/espais-del-rec/ [28 abr 2017]

15 "Rutes a l'entorn del Ter 2. Manlleu, punt de partida. Canal, ciutat i cotó" Canal, ciudad y algodón. Itinerario por el canal de Manlleu y el paisaje urbano de la primera industrialización. Facilitado por J. Sabaté.
} 
La estructura urbana de Manlleu difiere de los otros ejemplos que estamos analizando. Es una población de menor tamaño, con muchas edificaciones aún con patio y calles anchas, pensadas para el tráfico rodado. Todo ello influye en la configuración de los espacios públicos. No se necesitan tantas plazas que doten de luz o ventilación a las edificaciones o de lugares de encuentro a las personas. Uno de los espacios más representativos de esta localidad es la plaza ochocentista porticada del Ayuntamiento. Como contrapunto, el Museo del Ter, no configura en su acceso una plaza en el sentido tradicional, pero si construye un mirador al paisaje, en concreto al río, como punto de reflexión sobre sus telares desaparecidos. De hecho, el margen del río es protagonista en el recorrido propuesto por el Museo para conocer la historia de Manlleu.

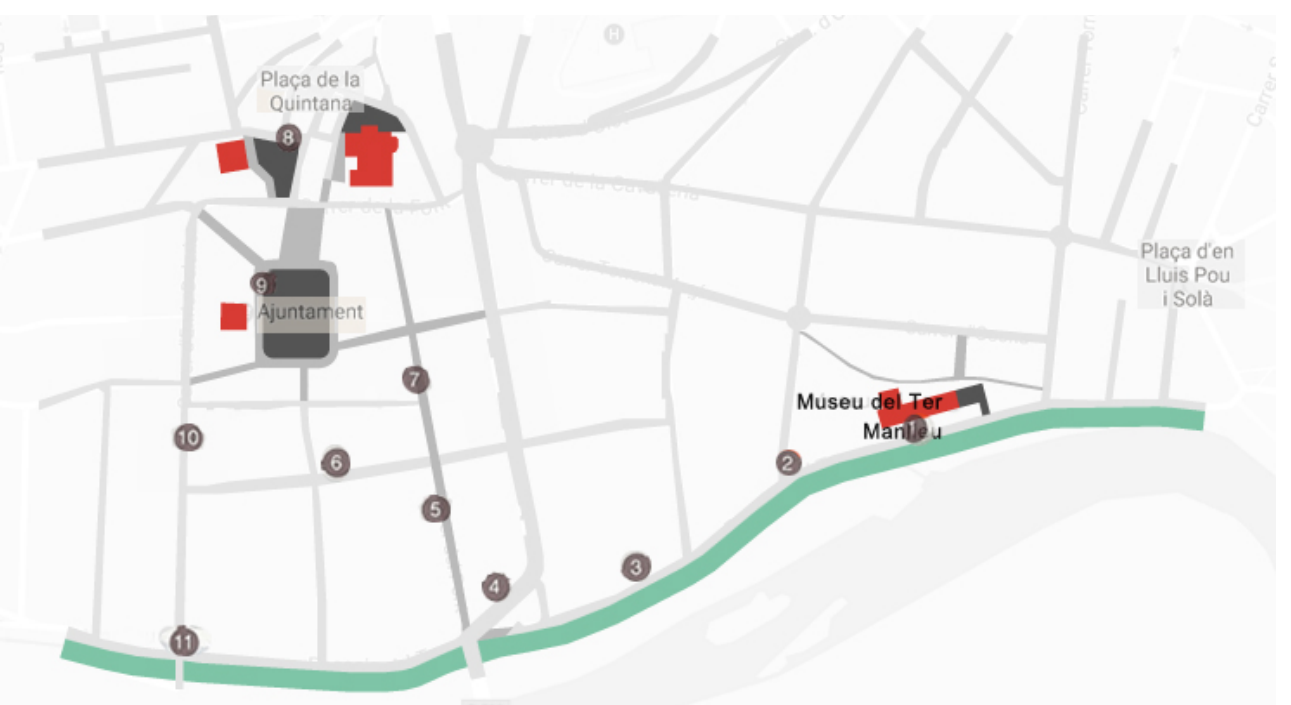

Gráfico 7. Equipamientos y espacios públicos del entorno del Museo del Ter. Elaboración propia sobre puntos del recorrido Canal, ciudad y algodón de Manlleu.

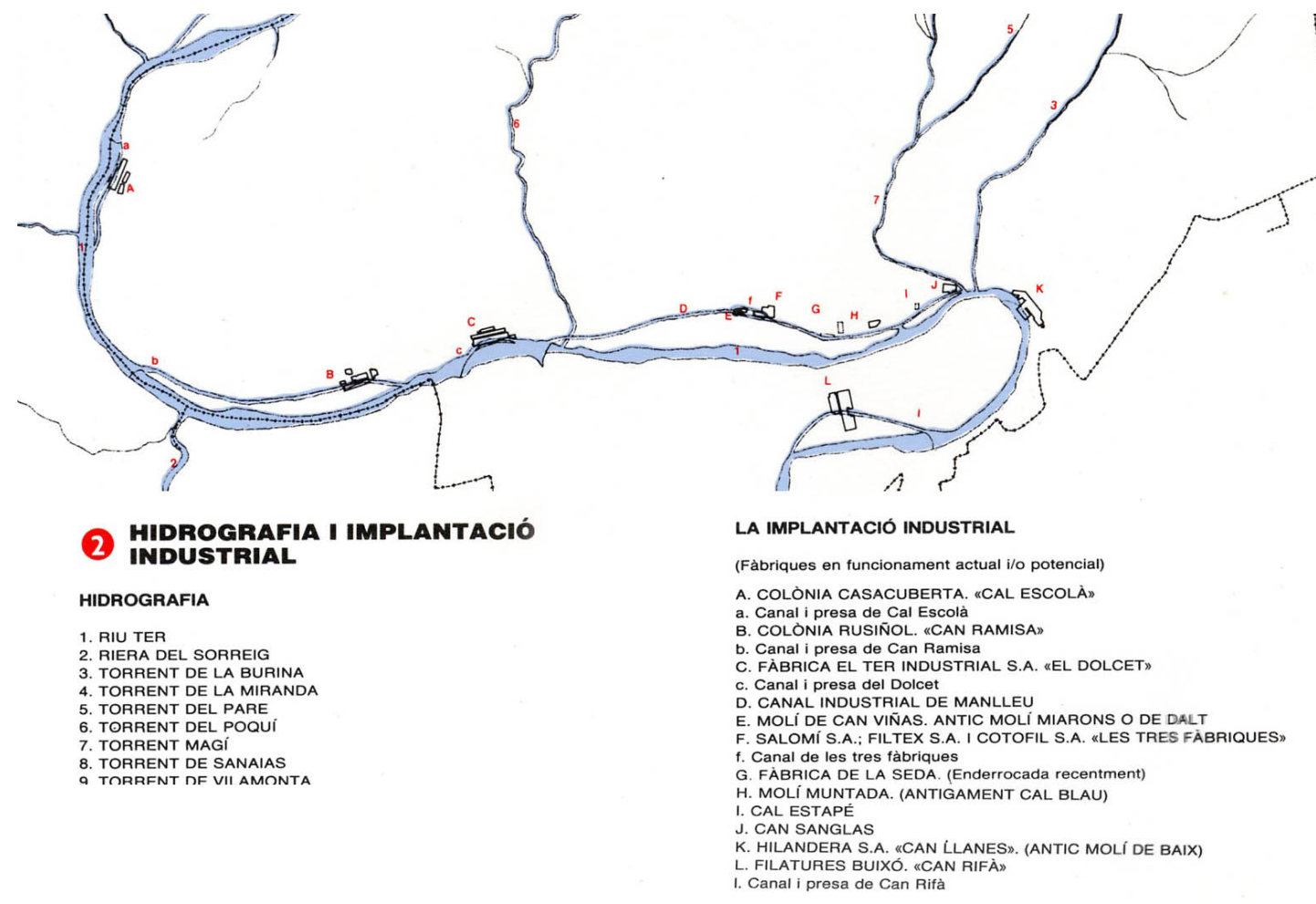

Figura 12. Fragmento del Documento que muestra la Morfología del término de Manlleu¹6.

16 Pujol i Mongay, E. (1990) Plano de Miquel Surinyach i Pla, para el Ayuntamiento de Manlleu. 
En Manlleu, el Museo Industrial del Ter, nos cuenta la historia de este río. "Está ubicado en la antigua fábrica Can Sanglas, creada en 1840, uno de los primeros edificios fabriles de la ciudad y de Cataluña. Es la última fábrica que aprovecha la energía del canal industrial de Manlleu y aún conserva dos turbinas." Además, gracias a su posición, "ha puesto en marcha unos recorridos turísticos por la orilla del Ter, donde se puede contemplar su patrimonio industrial y natural" (Casanelles, 2013, p.98). Si bien estos recorridos cubren una pequeña parte de la extensa gama de esclusas y fábricas ubicadas a esta altura del Ter. De hecho existen registros completos de las fábricas de la zona, como la imagen previa con las fábricas en activo hasta 1990, así como proyectos preparados para la puesta en valor de los meandros próximos al museo. Algunos apuestan por su potencial urbano y otros por mantener su conexión con el paisaje, es el caso de un estudio realizado por el equipo CCRS.

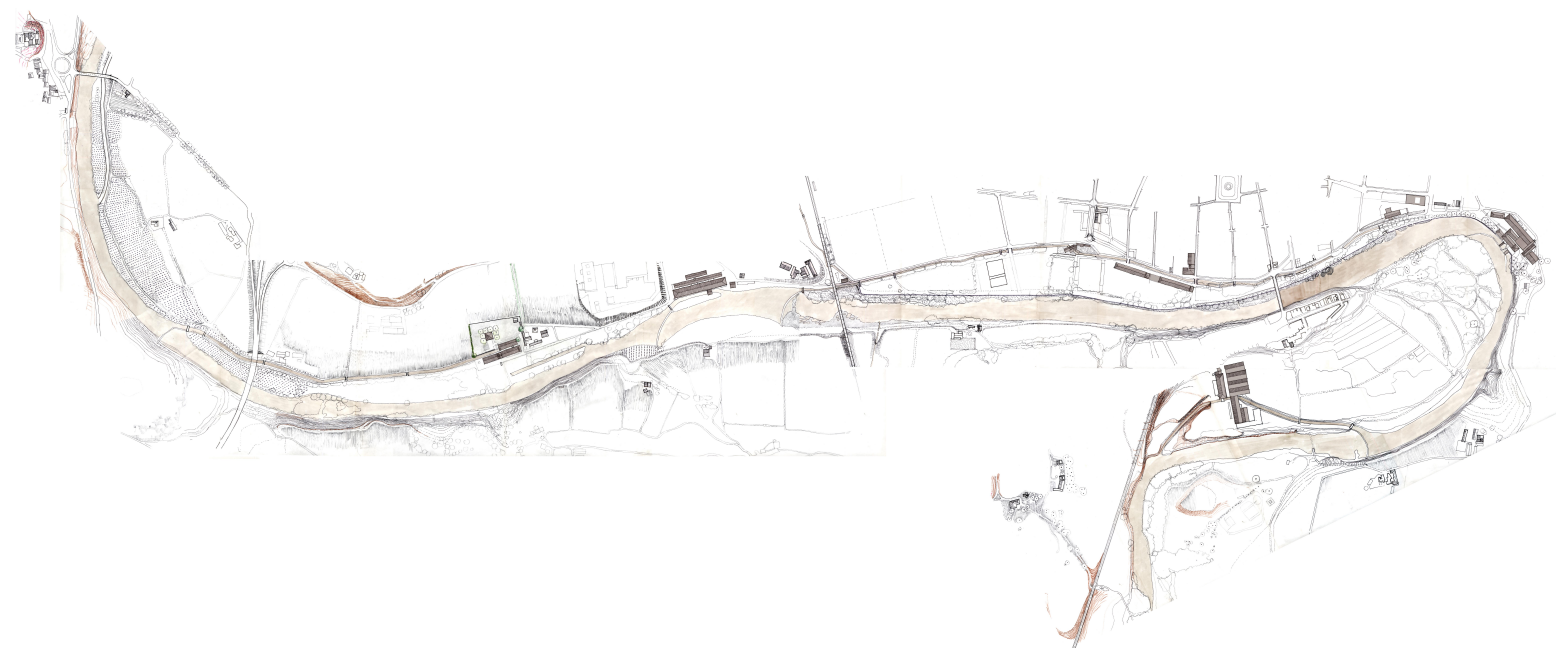

Figura 12. Fragmento del Plan director urbanístico de Patrimonio Industrial del Ter y del Freser.

Fuente: CCRS arquitectes (2009).

Acercándonos a Barcelona, escogemos el caso de la Fábrica Oliva Artés del MUHBA por su posición estratégica en el barrio industrial por excelencia: Poblenou. En cuanto a la red de espacios públicos de su entorno, podemos observar como la homogeneidad del plan del ensanche Cerdà,

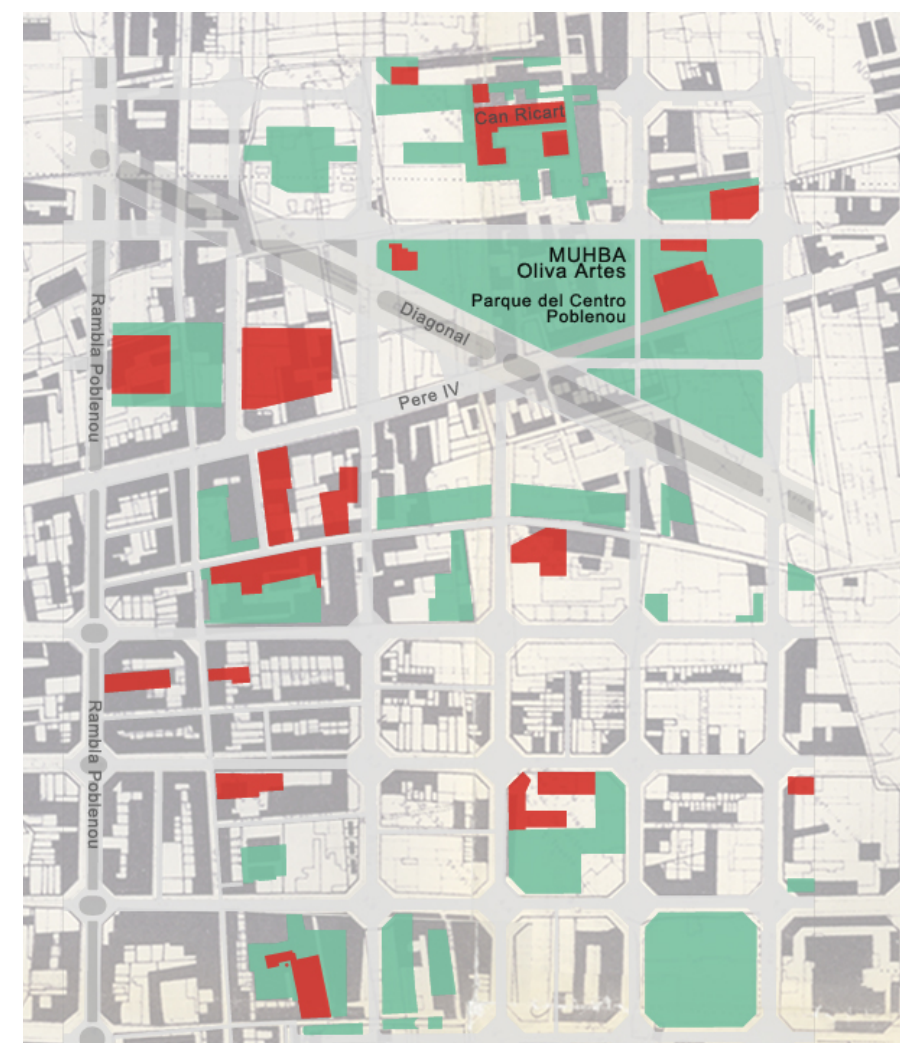
se ha adaptado en algunos puntos a la trama industrial preexistente. Esta Fábrica Cultural se sitúa en un nuevo parque triangular, atravesado por el histórico eje de Pere IV. Es una intervención mínima, que pone en valor el patrimonio de la zona, y se erige como lugar de encuentro frente a las transformaciones que aún están por llegar. El parque linda con la Avenida Diagonal, con el distrito 22@y con el antiguo complejo industrial y nuevo espacio público reivindicado: Can Ricart. Estos conjuntos se establecen como una sucesión de espacios públicos que conectan el pasado y el futuro del barrio.

Gráfico 8. Equipamientos y espacios públicos del entorno del MUHBA Oliva Artés. Elaboración propia sobre el plano: 1929. El desarrollo de la residencia y la industria sobre la trama Cerdà. Plan Especial Diagonal Poblenou (1987). 
El plano se superpone al documento con las principales fábricas (1929) previo al Plan Especial Diagonal Poblenou desarrollado por CCRS. Más tarde algunas de ellas se catalogaron con el plan 22@. Es relevante observar cómo, tanto las vías como la edificación antigua se concentra en el Sudoeste, alrededor de dicho eje, mientras a medida que avanzamos al Noreste aparecen más parques y una trama más regular. Todo ello culmina en el parque, que cumple la misión de rótula entre el antiguo eje de Pere IV y la nueva vía representativa de la ciudad, la Diagonal.

En este caso, la red de espacios públicos abiertos se ha grafiado en verde por su dimensión y caracterización más propia de los parques que de las plazas. La gran cantidad de espacios abiertos y equipamientos hace de este fragmento una parte peculiar de la ciudad; si bien la falta de jerarquía hace aún complicado leer recorridos peatonales claros más allá de la Diagonal y la Rambla del Poblenou. La fábrica Cultural Oliva Artés está trabajando para recuperar la vía Pere IV como eje de actividad del barrio, demostrando la influencia que estas instituciones tienen en la ciudad.

Por último cabe destacar una mirada a los recorridos del "Distrito de la Innovación", que nos ofrece el Ayuntamiento de Barcelona con motivo del 10 aniversario del 22@. En el mismo aparece una parada en el Parque del centro de Poblenou como lugar de interés natural y cultural, aunque también podría aparecer Oliva Artés en la ruta de patrimonio histórico-artístico. Además parece que la conexión que se realiza en este punto de Pere IV aparece cortada. Ambos aspectos indican que este caso, el más reciente, es el que menos influencia tiene en su entorno. Seguramente pesa el hecho de estar rodeado por un parque y su muro.

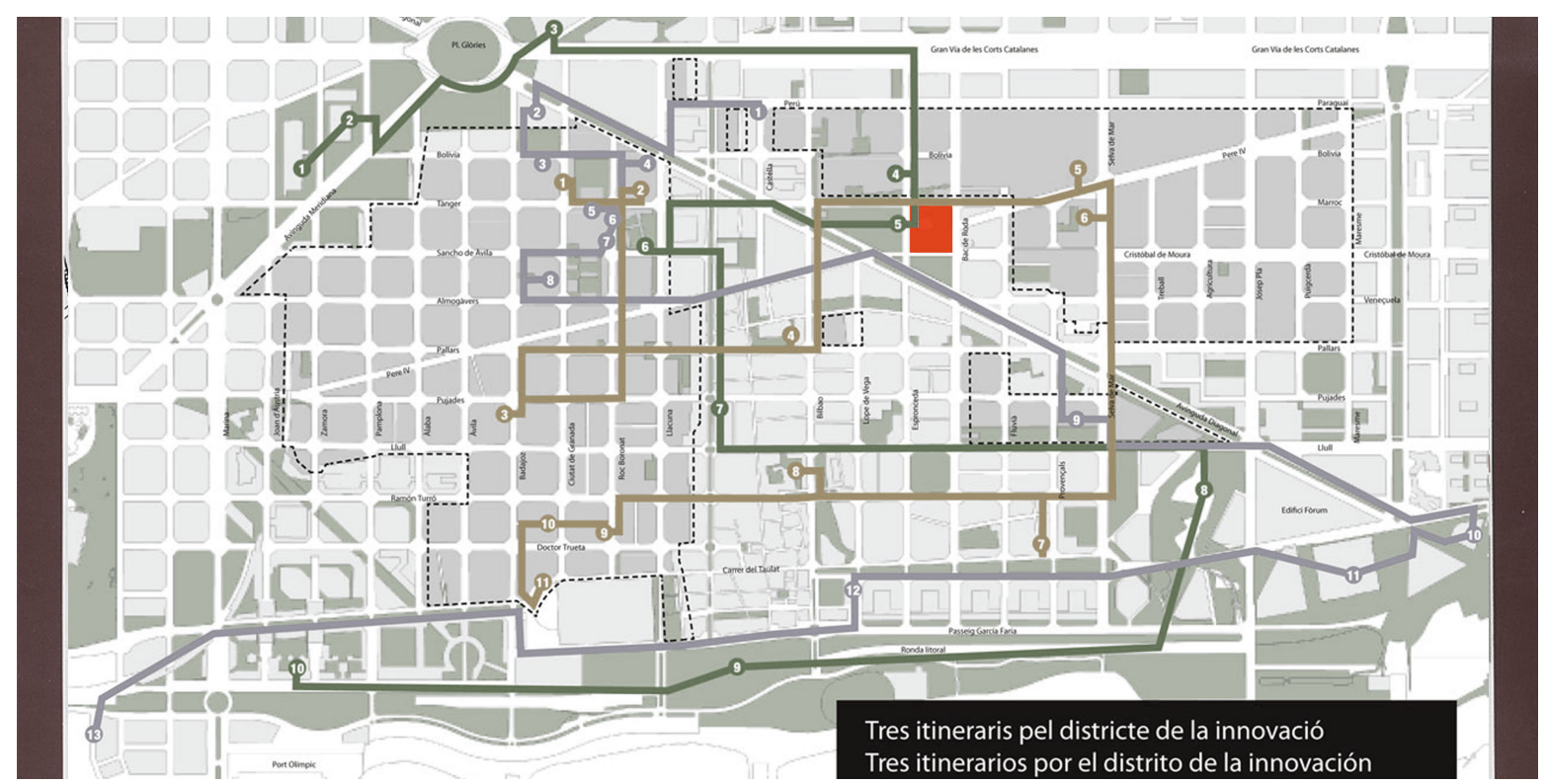

Figura 13. MUHBA Oliva Artés destacado sobre los itinerarios por el distrito 22@. Fuente: Ayuntamiento de Barcelona ${ }^{17}$.

En conclusión, tanto los elementos integrantes del Sistema Territorial del mNACTEC, como los del MUHBA son monumentos, que además de pertenecer a una gran red territorial innovadora, se deben a su contexto. Las Fábricas Culturales construyen más que un espacio interior, un espacio exterior rico, que atrae al peatón y genera nuevas dinámicas en las redes del espacio público próximo. En este aspecto, el museo no se debe solo a sus visitantes, sino también a sus vecinos. Otras construcciones pueden encerrarse en sí mismas, pero un equipamiento que promueve la cultura, debe contribuir a construir espacios públicos de calidad que inviten a sus residentes y visitantes a recorrerlo, generando encuentros que culminen en redes sociales complejas y diversas.

\section{Discusión}

Esta investigación muestra como con diferentes espacios, a priori inconexos, pero conectados mediante ciertas leyes, pueden establecerse redes que impulsen el desarrollo cultural a todas las

17 http://www.22barcelona.com/10x22barcelona/planol/?lang=es [28 Abril 2017] 
escalas. Vincular los museos nacionales a puntos alejados de las grandes urbes es una apuesta por la cohesión descentralizada, ya que se generan nuevos y pequeños nodos a través del territorio, suponiendo una clave estratégica para su organización. Además, se realiza mediante actuaciones sencillas como la conversión de una fábrica en museo, pero de gran impacto si se tienen en cuenta las necesidades del entorno. Por tanto, las redes culturales aportan poder indirecto, con actuaciones coordinadas consiguen transformar barrios o pueblos aparentemente obsoletos y demostrar que siguen vivos. En este proceso el papel de la administración es muy importante, por eso se han tomado casos públicos exitosos, como muestran los 30 años de trayectoria del mNACTEC o la buena acogida del sistema de sedes patrimoniales y actividades culturales del MUHBA.

Barcelona, que siempre ha apostado por ser una ciudad innovadora, lo hace ahora por ser una "megaregión creativa". A ello contribuye sin duda la descentralización de redes culturales como las analizadas. Frente a otras tendencias, que sitúan al museo del siglo XXI en distritos concentrados para turistas, Barcelona prefiere distribuir su actividad cultural en diferentes fragmentos de la ciudad y el territorio. Eso sí, manteniendo la calidad gracias a diferentes redes en las que las Fábricas Culturales juegan un rol fundamental. Este tipo de museos parte de la tradición obrera y se adapta a las necesidades de la sociedad actual. Una sociedad heterogénea que demanda ofertas culturales variadas y de calidad.

El análisis cronológico de las diferentes redes del Patrimonio Industrial a nivel internacional y su implementación a escala local, nos permite entender mejor el momento contemporáneo en el que la conectividad es un componente imprescindible, pero no solo entre puntos del territorio, sino también, entre los diferentes fragmentos urbanos. Las redes analizadas apuestan por la promoción de las Fábricas como espacios culturales y punto de partida de recorridos y proyectos futuros. Cada actuación refuerza en sí misma la idea del sistema y genera sinergias en sus proximidades. Estas redes son además pioneras en la corriente descentralizadora, con las ventajas que eso supone a todas las escalas.
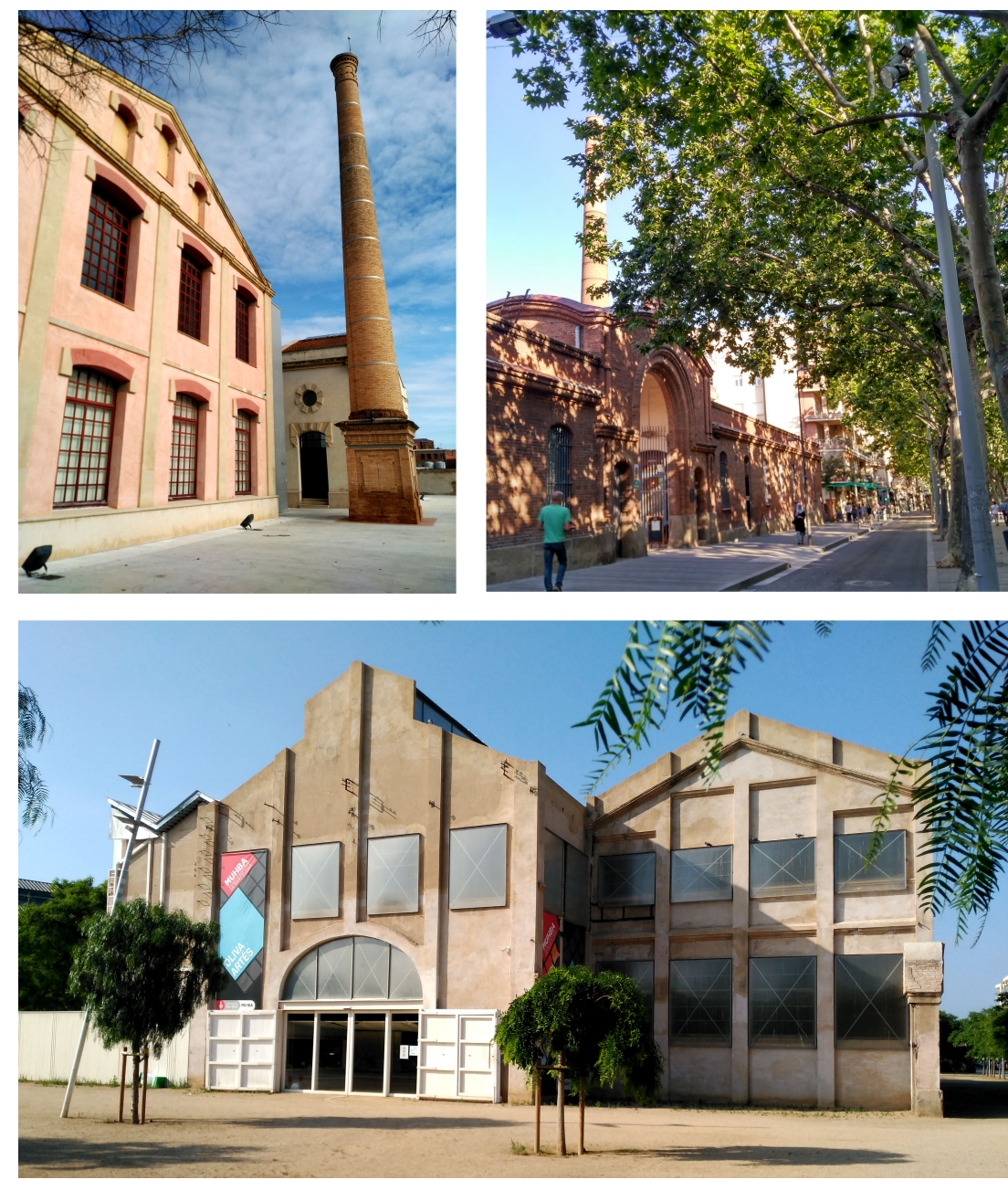

Figura 14. Imágenes representativas de 3 de los casos de estudio: Museo de la Piel en Igualada, sede del Museo de la Ciencia y la Técnica de Cataluña en Terrassa y Museo de Historia de Barcelona Oliva Artés en Poblenou. Fuente: Captura propia. 
Las Fabricas Culturales contribuyen a extender una cultura común sobre la industrialización más allá de las fronteras entre las grandes urbes y el resto del territorio, o entre los centros urbanos y la periferia. A nivel territorial, el sistema favorece la comunicación entre diferentes ciudades, estableciendo rutas de intercambios. A nivel urbano, permite redistribuir los visitantes en zonas con menor presión, puesto que suelen ubicarse en áreas con poco patrimonio de otro tipo y espacios desocupados. A escala del fragmento tienen un gran poder transformador, ya que suponen polos de atracción que favorecen nuevos recorridos, reclamando indirecta o directamente, en forma de plazas de acceso, más espacios públicos. Si queremos comunidades más conectadas, debemos tener en cuenta no solo las infraestructuras de la mobilidad, sino también las redes culturales. Para cohesionar el territorio, necesitamos más ejemplos de elementos que construyan tanto conexiones a través del territorio, como puentes entre el pasado y el futuro de las ciudades. Espacios como las Fábricas Culturales, donde se trabaja con materiales de la memoria y la situación presente, para dar forma a un futuro en el que los espacios culturales comunitarios jueguen un rol tan fundamental como el que han tenido en la actualidad.

\section{Referencias}

Argemi, J. (2014). El silenci dels vapors. Sabadell: una aproximació. (màster universitari) urbanisme. Departament d'Urbanisme i Ordenació del Territori, Universitat Politècnica de Catalunya, Espanya.

Ayuntamiento de Barcelona, Instituto de Cultura (2008). Síntesis del nuevo Plan Estratégico del MUHBA.

Baran, P. (1964). On Distributed Communication Networks. Rand Corporation, Santa Monica, California.

Bell, D. (1973). The Coming of Post-Industrial Society. New York: Basic Books.

Bergeron, L. (2002). El patrimonio industrial, ¿qué hacer? en Patrimonio industrial: lugares de la memoria. España: Incuna.

Caballé, F. (2010). Desaparece el barrio de Icària, nace la Vila Olímpica. Biblio 3W. Revista Bibliográfica de Geografía y Ciencias Sociales, Universidad de Barcelona, 15 (895).

Casanelles, E. (2007). El Sistema territorial del mNACTEC: bases i conceptes.

Casanelles, E. (2013). Un museu per a un país: el Sistema Territorial del mNACTEC pp.22-18 Cataluña: mNACTEC

Dennis, R. (2008). Urban modernity, networks and places. England: Cambridge University Press

Escobedo, N. (2014). Los No lugares y la arquitectura del espacio turístico.

Escolar, H. (2001). La biblioteca de Alejandría. España: Gredos, p.85.

Esteban, I. (2007). El efecto Guggenheim, del espacio basura al ornamento. Barcelona: Editorial Anagrama.

Florida, R. (2009). Las ciudades creativas: Por qué donde vives puede ser la decisión más importante de tu vida. España: Paidós Ibérica.

Kazepov, Y. y Sennett, R. (2008). Capitalism and the City: Globalization, Flexibility, and Indifference. En Cities of Europe: Changing Contexts, Local Arrangements, and the Challenge to Urban Cohesion, Oxford: Blackwell. pp.109-122.

Lord, G. y Blankenberg N. (2015). Cities, Museums and Soft Power. Washington: AAM Press.

Meinrad (2016). European Industrial Heritage: The International Story. Contribución del ERIH para el año Europeo del Patrimonio. 
Méndez, F. P. (1999). Experiencias Recientes. Debates abiertos en La ciudad deseada. Valorización cultural de la ciudad histórica, su evolución sostenible y su futuro en la previsible ordenación del territorio. Castilla y León: Fundación del Patrimonio Histórico.

Monclús, F. J. (2006) Culture, Urbanism and Planning. Aldershot, UK; p.293.

Montaner, J. M., Aparici I. y Navarro P. (2016). Barcelona espais singulars. Barcelona: Comanegra.

Nikolić, M. (2012) City of Museums: Museum Cluster as a Manifesto of the Paradigm Shift. Barcelona: UPC.

Pardo, C. J. (2016). El Patrimonio industrial en España. Paisajes, lugares y elementos singulares. España: Akal.

Perarnau, J. (2014). Tot s'hi val en la recuperació del patrimoni industrial? Revista Dovella, 114 ,pp. 19-23.

Rothstein, P. A. (2014). Las Fábricas de Creación de Barcelona. (Trabajo de fin de grado) Ciencias politicas y de la administracion. Universitat de Barcelona.

Sabaté, J. (2003). El patrimonio como recurso básico para un nuevo modelo de desarrollo. Urban 9.

Sabaté, J. (2008). Globalización y estrategias Urbanísticas: Un balance del desarrollo reciente de Barcelona. Cuaderno Urbano, 8.

Tatjer M. (2006). La industria en Barcelona (1832-1992). Factores de localización y cambio en las áreas fabriles: del centro histórico a la región metropolitana. Barcelona: UPC.

Tielve, N. (2002). Patrimonio industrial, Cultura, Arte y Sociedad. Propuestas y Realidades en Patrimonio industrial: lugares de la memoria. Barcelona: UPC. pp. 146-151

Touraine, A. (1969) La societé post-industrielle. Denoël, p.319. 